Article

\title{
Brazilian Tensile Strength of Anisotropic Rocks: Review and New Insights
}

\author{
Tianshou Ma ${ }^{1,2, *} \mathbb{1}$, Nian Peng ${ }^{1}$, Zhu Zhu ${ }^{3}$, Qianbing Zhang ${ }^{4}$, Chunhe Yang ${ }^{2}$ and Jian Zhao ${ }^{4}$ \\ 1 State Key Laboratory of Oil \& Gas Reservoir Geology and Exploitation, Southwest Petroleum University, \\ Chengdu 610500, China; pengnian023@gmail.com \\ 2 State Key Laboratory of Geomechanics and Geotechnical Engineering, Institute of Rock and Soil Mechanics, \\ Chinese Academy of Sciences, Wuhan 430071, China; chyang@whrsm.ac.cn \\ 3 College of Management and Science, Chengdu University of Technology, Chengdu 610059, China; \\ zhuzhu_cut@163.com \\ 4 Department of Civil Engineering, Monash University, Melbourne, VIC 3800, Australia; \\ qianbing.zhang@monash.edu (Q.Z.); jian.zhao@monash.edu (J.Z.) \\ * Correspondence: matianshou@126.com; Tel.: +86-159-8237-4460
}

Received: 27 December 2017; Accepted: 25 January 2018; Published: 30 January 2018

\begin{abstract}
Strength anisotropy is one of the most distinct features of anisotropic rocks, and it also normally reveals strong anisotropy in Brazilian test Strength ("BtS"). Theoretical research on the "BtS" of anisotropic rocks is seldom performed, and in particular some significant factors, such as the anisotropic tensile strength of anisotropic rocks, the initial Brazilian disc fracture points, and the stress distribution on the Brazilian disc, are often ignored. The aim of the present paper is to review the state of the art in the experimental studies on the "BtS" of anisotropic rocks since the pioneering work was introduced in 1964, and to propose a novel theoretical method to underpin the failure mechanisms and predict the "BtS" of anisotropic rocks under Brazilian test conditions. The experimental data of Longmaxi Shale-I and Jixi Coal were utilized to verify the proposed method. The results show the predicted "BtS" results show strong agreement with experimental data, the maximum error is only $\sim 6.55 \%$ for Longmaxi Shale-I and $\sim 7.50 \%$ for Jixi Coal, and the simulated failure patterns of the Longmaxi Shale-I are also consistent with the test results. For the Longmaxi Shale-I, the Brazilian disc experiences tensile failure of the intact rock when $0^{\circ} \leq \beta_{\mathrm{w}} \leq 24^{\circ}$, shear failure along the weakness planes when $24^{\circ} \leq \beta_{\mathrm{w}} \leq 76^{\circ}$, and tensile failure along the weakness planes when $76^{\circ} \leq \beta_{\mathrm{w}} \leq 90^{\circ}$. For the Jixi Coal, the Brazilian disc experiences tensile failure when $0^{\circ} \leq \beta_{\mathrm{w}} \leq 23^{\circ}$ or $76^{\circ} \leq \beta_{\mathrm{w}} \leq 90^{\circ}$, shear failure along the butt cleats when $23^{\circ} \leq \beta_{\mathrm{w}} \leq 32^{\circ}$, and shear failure along the face cleats when $32^{\circ} \leq \beta_{\mathrm{w}} \leq 76^{\circ}$. The proposed method can not only be used to predict the "BtS" and underpin the failure mechanisms of anisotropic rocks containing a single group of weakness planes, but can also be generalized for fractured rocks containing multi-groups of weakness planes.
\end{abstract}

Keywords: anisotropic rocks; Brazilian disc test; tensile strength; failure patterns; anisotropy

\section{Introduction}

Anisotropy is one of the most distinct features considered in engineering rock mechanics, and is applied in civil, mining, geothermal, geo-environmental, and petroleum engineering [1-4]. Most anisotropic rocks, such as shale, mudstone, sandstone, slate, gneiss, schist, coal, and marl, present anisotropic mechanical behavior, and these anisotropic rocks usually play an important role in rock engineering. Gas shale has received increasing attention recently, and its mechanical behavior (compressive, shear, tensile and fracture behavior) plays an important role in shale gas extraction [5-8]. The mechanical behavior is concerned with wellbore collapse and leakage in the process of drilling, and hydraulic fracturing during the process of exploitation [9-12]. 
The most common anisotropic rocks are usually transverse isotropic, due to their distinct layered structure that originates from their special deposit sediments and the sedimentary environment. To investigate rock anisotropy, many researchers have conducted numerous experimental and theoretical studies on anisotropic rocks [1-3,13-19]. The results have indicated that the mechanical properties of anisotropic rocks vary with sampling direction, and engineering applications that do not consider the anisotropic behavior usually produce errors of differing magnitudes, depending on the extent of anisotropy [2]. However, most of these studies focus on the anisotropy of deformation, modulus, compressive strength, and shear strength, while the anisotropy of tensile strength is seldom studied. The test methods of tensile strength can be divided into the Direct Tensile Test (DTT) method and the Indirect Tensile Test (ITT) method. The DTT method is seldom utilized to test rock-like materials, due to the difficulty of the experimental set-up [20,21]. In 1943, a new type of ITT method, the Brazilian Disc Test (BDT) method, was developed to test the tensile strength of concrete [22,23]. The tensile strength is usually referred to as Indirect Tensile Strength (ITS) or Brazilian Tensile Strength (BTS). The BDT method has found application mainly in investigations of homogeneous rock-like materials [24-29]. The pioneering work on the anisotropy of BTS was conducted for siltstone, sandstone, and mudstone by Hobbs (1964) [30]. From then on, several researchers have begun to pay attention to the anisotropy of BTS, but most of them focus on experimental research to understand the influence of the foliation-loading angle on the BTS [25,26,31-55]. Barla and Innaurato found that only a few specimens meet the assumption of tensile failure mode starting from the center of a Brazilian disc [31]. In other words, the outcome of the BDT method is definitely not the real tensile strength of the Brazilian disc because it does not meet the basic assumptions of BDT method. In order to avoid ambiguity with the Brazilian Tensile Strength (BTS), another term, the Brazilian test Strength ("BtS"), was used to represent the test strength of anisotropic rocks under the BDT conditions in this paper.

In recent years, a few researchers have therefore proposed some analytic solutions using the Single Plane of Weakness (SPW) theory to find the interior difference between the "BtS" and traditional BTS. Liu et al. (2013) considered the anisotropic strength to propose a "BtS" criterion for slate rocks, the central stresses on the Brazilian disc and the SPW theory were combined to determine the "BtS" [39]; $\mathrm{Li}$ et al. also proposed a "BtS" criterion for jointed coal rocks, the SPW theory was generalized into two groups of weakness planes [51]. However, the above theoretical methods have some insufficiencies: (1) Only the central stress on the Brazilian disc is involved, the critical state of stress may occur in points different than the center, thus, the stress concentration on the Brazilian disc is ignored; (2) The influence of anisotropic tensile strength is ignored; (3) Some of the predicted results are inconsistent with the universal law, the transverse "BtS" is usually higher than the longitudinal "BtS", but the transverse "BtS" is always equals to the longitudinal "BtS" in the current model.

In this paper, we present a review and some new insights into the anisotropic "BtS" of anisotropic rocks to predict the "BtS" and failure mode under BDT conditions. First, we reviewed the experimental studies on the "BtS" of anisotropic rocks from the viewpoint of experimental results and failure patterns, and the typical failure patterns were newly classified based on the failure mechanisms. Second, a novel theoretical method was proposed to underpin the failure mechanisms of anisotropic rocks in Brazilian disc tests. Finally, the experimental data of Longmaxi Shale-I and Jixi Coal were used to verify the proposed method.

\section{Overview of the BDT for Anisotropic Rocks}

\subsection{Anisotropic Degrees of "BtS" for Anisotropic Rocks}

To present the anisotropy of "BtS" for anisotropic rocks, this study identified a large number of BDT results of different anisotropic rocks from published literature, and Table 1 presents the main research regarding BDTs on anisotropic rocks. The anisotropic index can be defined to characterize 
the anisotropic degree of " $\mathrm{BtS}$ ", and the anisotropic index is the ratio of maximum " $\mathrm{BtS}$ " to minimum "BtS" [56]:

$$
A I=\frac{B t S_{\max }}{B t S_{\min }}
$$

Table 1. The BDT results of various layered rocks.

\begin{tabular}{|c|c|c|c|c|c|c|}
\hline No. & Rock Types & References & Min. BtS/MPa & Max. BtS/MPa & $A I$ & Group \\
\hline 1 & Permian Shale & [5] & 13.61 & 21.63 & 1.59 & \multirow{18}{*}{ Shale } \\
\hline 2 & Green River Shale & [5] & 11.46 & 17.24 & 1.51 & \\
\hline 3 & Boryeong Shale & [2] & 6.40 & 13.60 & 2.13 & \\
\hline 4 & Mancos Shale-I & [40] & 2.47 & 3.22 & 1.30 & \\
\hline 5 & Mancos Shale-I in Oil & [40] & 2.47 & 3.95 & 1.60 & \\
\hline 6 & Mancos Shale-II & [42] & 2.92 & 6.10 & 2.09 & \\
\hline 7 & GR Shale-I & [42] & 2.45 & 7.42 & 3.02 & \\
\hline 8 & GR Shale-II & [42] & 4.49 & 9.58 & 2.13 & \\
\hline 9 & GR Shale-III & [42] & 3.76 & 7.50 & 1.99 & \\
\hline 10 & GR Shale-IV & [42] & 8.71 & 13.22 & 1.52 & \\
\hline 11 & Longmaxi Shale-I & [47] & 3.47 & 6.61 & 1.91 & \\
\hline 12 & Longmaxi Shale-II & [48] & 4.60 & 10.81 & 2.35 & \\
\hline 13 & Longmaxi Shale-III & {$[53,54]$} & 3.32 & 7.64 & 2.30 & \\
\hline 14 & X Shale (Air Dry) & {$[46]$} & 2.48 & 6.01 & 2.42 & \\
\hline 15 & X Shale (Staturated) & {$[46]$} & 1.10 & 3.09 & 2.81 & \\
\hline 16 & Wolfcamp Shale & {$[42,43]$} & 5.78 & 16.11 & 2.79 & \\
\hline 17 & Mudstone-I & {$[44]$} & 0.81 & 4.06 & 5.01 & \\
\hline 18 & Mudstone-II & [44] & 1.32 & 5.45 & 4.13 & \\
\hline 19 & Type I Sandtone & [57] & 3.86 & 5.86 & 1.52 & \multirow{9}{*}{ Sandstone } \\
\hline 20 & Type II Sandtone & {$[57]$} & 0.97 & 4.34 & 4.50 & \\
\hline 21 & Modave Sandstone & {$[34,35]$} & 9.53 & 15.13 & 1.59 & \\
\hline 22 & Arkansas Sandstone & [5] & 9.57 & 11.71 & 1.22 & \\
\hline 23 & Postaer Sandstone & [25] & 3.39 & 4.14 & 1.22 & \\
\hline 24 & Bedded Sandstone & [50] & 11.64 & 13.28 & 1.14 & \\
\hline 25 & Qom Sandstone Type I & [17] & 4.24 & 8.48 & 2.00 & \\
\hline 26 & Qom Sandstone Type II & [17] & 4.36 & 12.06 & 2.77 & \\
\hline 27 & Qom Sandstone Type III & [17] & 5.73 & 9.36 & 1.63 & \\
\hline 28 & Herbeumont Slate & [33] & 0.37 & 20.00 & 53.59 & \multirow{4}{*}{ Slate } \\
\hline 29 & Huaihua-I Slate & [37] & 6.71 & 12.21 & 1.82 & \\
\hline 30 & Huaihua-II Slate & [39] & 3.55 & 11.80 & 3.32 & \\
\hline 31 & Mosel Slate & [45] & 3.80 & 15.56 & 4.10 & \\
\hline 32 & Valle di Susa Gneiss & [31] & 3.28 & 4.56 & 1.39 & \multirow{5}{*}{ Gneiss } \\
\hline 33 & Asan Gneiss & [2] & 6.20 & 18.97 & 3.06 & \\
\hline 34 & Freiberger Gneiss & [25] & 5.80 & 16.75 & 2.89 & \\
\hline 35 & Leubsdorfer Gneiss & [25] & 8.67 & 17.66 & 2.04 & \\
\hline 36 & XX Layered Gneiss & [52] & 12.99 & 19.68 & 1.52 & \\
\hline 37 & Val Malenco Schist & [31] & 2.49 & 6.83 & 2.75 & \multirow{3}{*}{ Schist } \\
\hline 38 & Yeoncheon Schist & [2] & 2.60 & 17.23 & 6.63 & \\
\hline 39 & Wudang Schist & [38] & 1.12 & 3.26 & 2.90 & \\
\hline 40 & XZY Coal (Dry) & [58] & 4.61 & 5.46 & 1.18 & \multirow{3}{*}{ Coal } \\
\hline 41 & XZY Coal (Saturated) & [59] & 4.03 & 5.26 & 1.30 & \\
\hline 42 & Jixi Coal & [51] & 0.35 & 0.63 & 1.80 & \\
\hline 43 & Marl-I & [44] & 2.53 & 4.07 & 1.61 & \multirow{2}{*}{ Marl } \\
\hline 44 & Marl-II & [44] & 2.44 & 4.44 & 1.82 & \\
\hline
\end{tabular}

To present the anisotropic degree of "BtS" for different rocks, Figure 1 compares the maximum and minimum "BtS" for various anisotropic rocks. The limits of the anisotropic index for different rocks, including shale, sandstone, slate, gneiss, schist, coal and marl, are listed in Table 2, where the anisotropic degree of tensile strength can be distinguished easily. The following conclusions can be drawn: (1) The minimum "BtS" is always lower than $15 \mathrm{MPa}$, while the maximum " $\mathrm{BtS}$ " is lower than $25 \mathrm{MPa}$, as shown in Figure 1. Thus, the tensile strength is very weak compared with compressive strength. (2) The anisotropy of tensile strength of various anisotropic rocks is quite 
significant. The anisotropic index is larger than 1 for all of these anisotropic rocks, more than half (approximately 23 points) of these anisotropic rocks are larger than 2, and most of them are smaller than 4, as shown in Figure 1 and Tables 1 and 2.

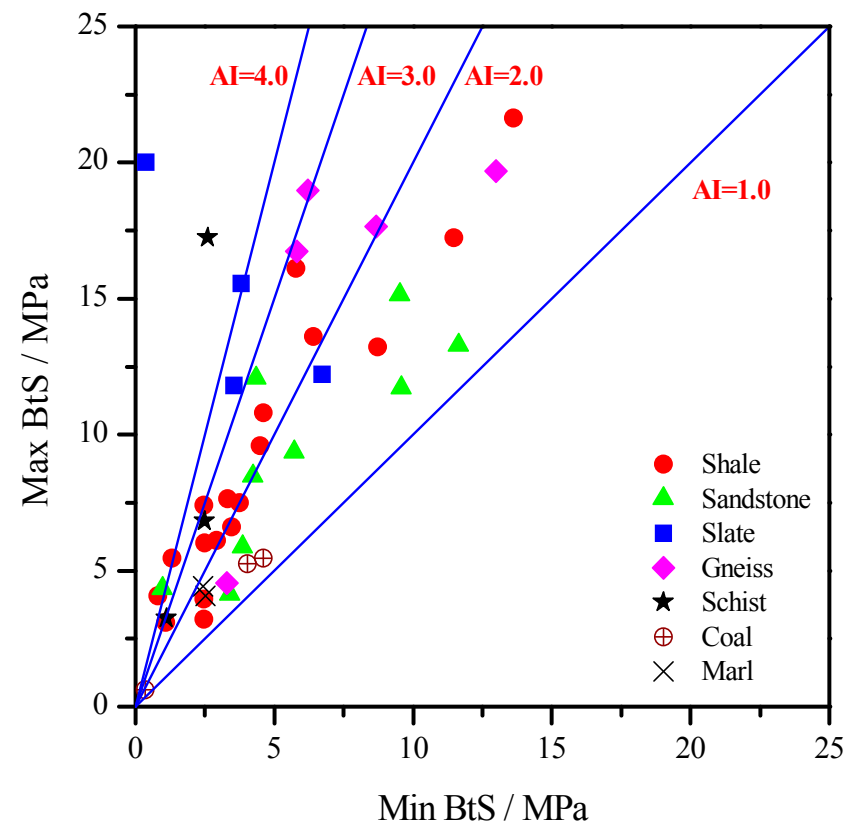

Figure 1. Plot of the maximum versus minimum "BtS" of various anisotropic rocks.

Table 2. The statistical results of anisotropic degree for various layered rocks.

\begin{tabular}{cccc}
\hline No. & Rock Types & Anisotropic Index & Anisotropic Degree [56] \\
\hline 1 & Shale & $1.30-5.01$ & Weak-Strong \\
2 & Sandstone & $1.14-4.50$ & Weak-Strong \\
3 & Slate & $1.82-4.10(53.59)$ & Weak-Strong (Ultra-strong) \\
4 & Gneiss & $1.39-3.06$ & Weak-Medium \\
5 & Schist & $2.75-6.63$ & Medium-Strong \\
6 & Coal & $1.18-1.80$ & Weak \\
7 & Marl & $1.61-1.82$ & Weak \\
\hline
\end{tabular}

\subsection{Variations of "BtS" with Loading Direction}

The above results and figures cannot reveal the variation of "BtS" with loading direction, therefore, this study identified a large number of BDT results of different shale rocks from the literature $[17,40-48,53,54,60,61]$. In particular, there are six types of shale or mudstone rocks, and the plot of "BtS" versus loading direction is shown in Figure 2. It is clearly seen that the "BtS" of shale rocks roughly decrease with the complementary angle $\left(\beta_{\mathrm{W}}\right)$ of foliation-loading angle, as indicated by the arrows in Figure 2. The "BtS" is usually lowest when the weakness plane is parallel to the loading direction, and it is usually highest when the weakness plane is perpendicular to the loading direction. Sometimes, the lowest "BtS" does not occur when the weakness plane is parallel to the loading direction, but instead at a highly-deviated angle. 

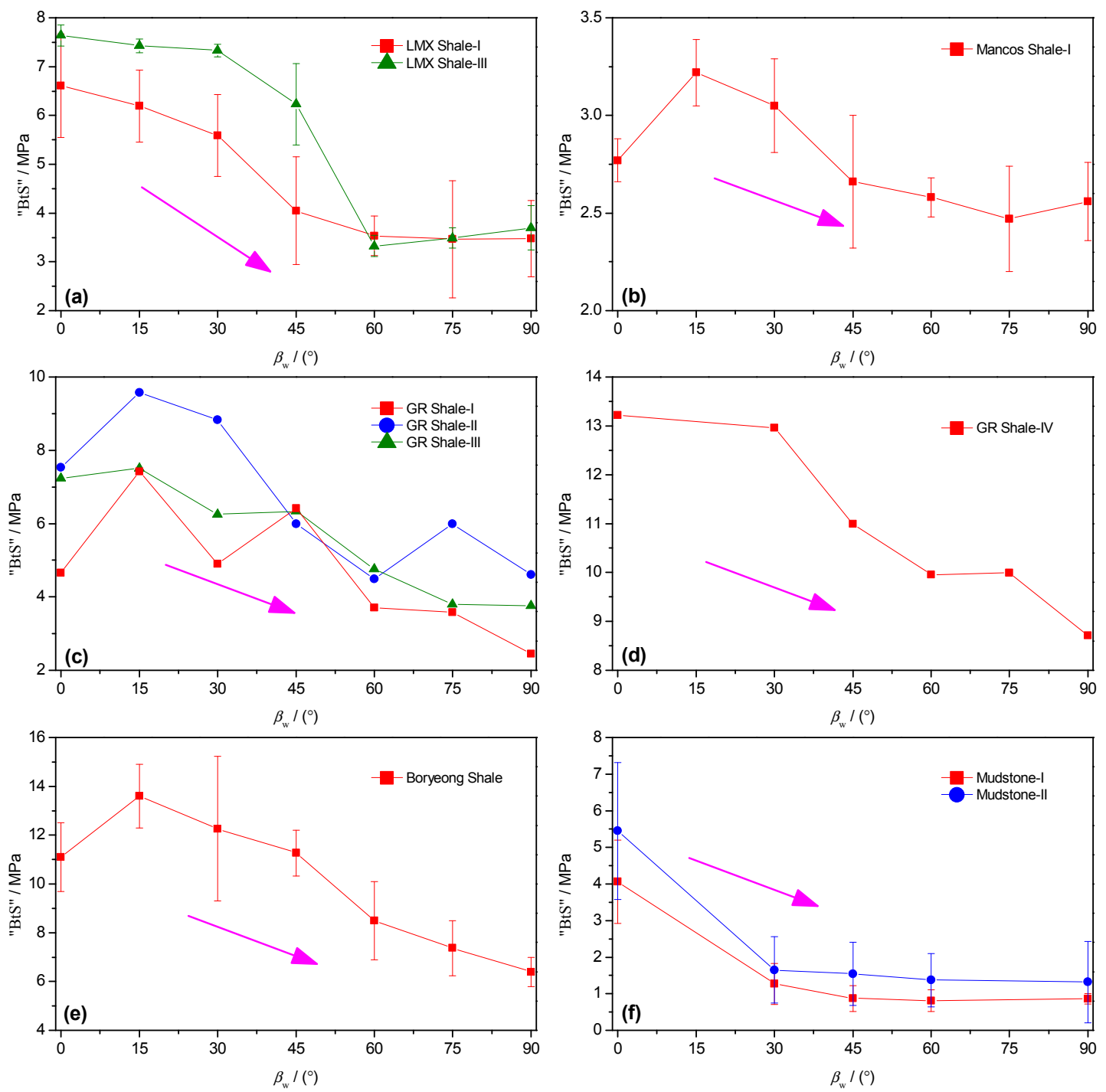

Figure 2. Plot of "BtS" versus $\beta_{\mathrm{w}}$ for various shale rocks, where the angle $\beta_{\mathrm{w}}$ represents the complementary angles of foliation-loading angle. (a) Longmaxi Shale-I [47] and Longmaxi Shale-III [53]; (b) Mancos Shale [40]; (c) GR Shale-I, -II, and -III [60]; (d) GR Shale-IV [60]; (e) Boryeon Shale [61]; and (f) Mudstone-I and -II [44].

\subsection{Typical Failure Modes}

To reveal the failure mechanisms of anisotropic rocks, shale rock can be taken as an example, this study identified some typical failure photographs of five types of shale rocks (including Longmaxi Shale-I, Longmaxi Shale-III, Mancos Shale-I, GR Shale-III, and Boryeon Shale). The failure patterns of these photographs has been redrawn and is shown in Figure 3. In the classical BDT theory, the initial failure point occurs at the center of the disc, but most of the photographs are inconsistent with the connotative assumption of the BDT theory (see Figure 3). Barla and Innaurato classified the typical failure patterns into three types based on their occurrence on testing the 28 discs of schist: (1) Failure along laminations, (2) Failure along line of loading, and (3) Otherwise; their results also indicated that the type of failure can be classified in tensile and shear. Tavallali and Vervoort [34-36] sorted the typical failure patterns into three types (see Figure 4): (1) Layer activation, (2) Central fracture, and (3) Non-central fracture. Tan et al. [45] sorted the typical failure modes for Brazilian disc tests on transversely isotropic rocks using laboratory testing and numerical simulations, and the typical failure was classified into five types (see Figure 5): (1) Pure tensile failure along the bedding, (2) Pure shear 
failure along the bedding, (3) Mixed-mode failure in the bedding and rock matrix (primarily caused by shear failure), (4) Mixed-mode failure in the bedding and rock matrix (primarily caused by tensile failure), (5) Pure tensile failure across the rock matrix. The classified method of Tan et al. (2015) [45] looks more reasonable, due to the failure mechanisms of the Brazilian disc being involved.

(a)

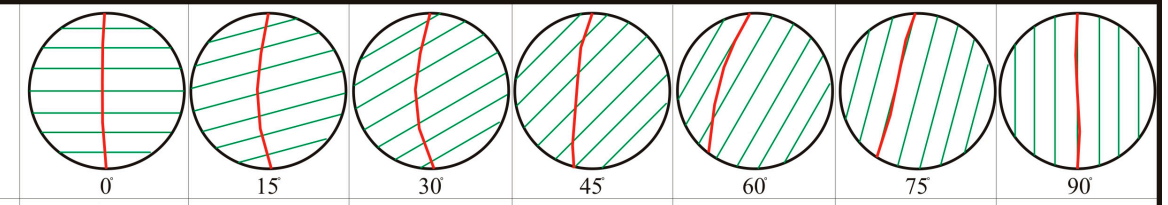

(b)

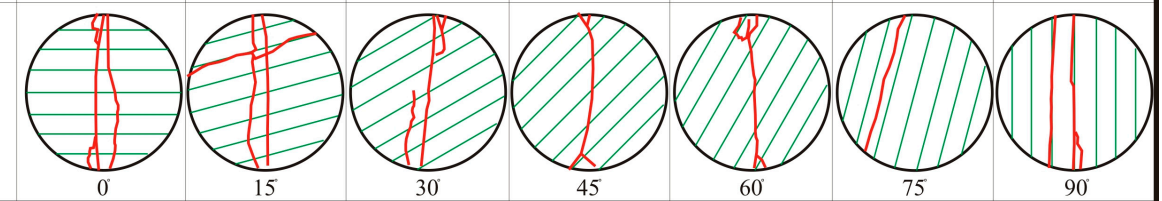

(c)

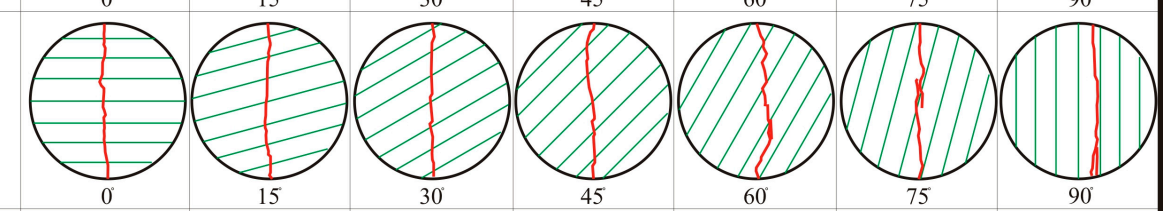

(d)

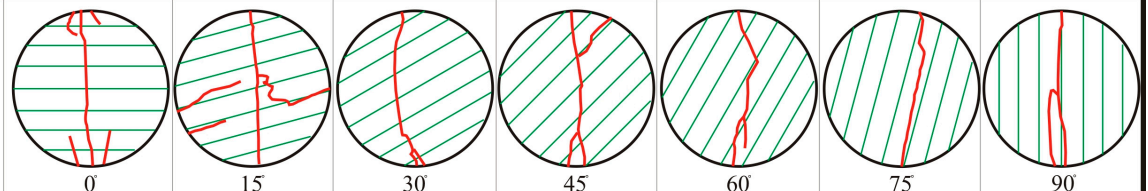

(e)

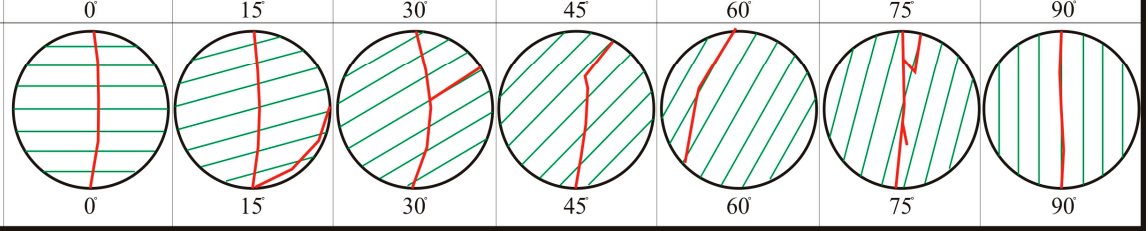

Figure 3. Sketches of failure patterns of oriented Brazilian disc for five kinks of typical shale rocks. (a) Longmaxi Shale-I [47]; (b) Longmaxi Shale-III [53]; (c) Mancos Shale-I [40]; (d) GR Shale-III [60]; and (e) Boryeon Shale [61].
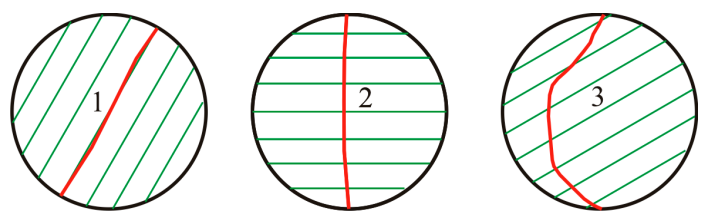

Figure 4. Schematic of three kinds of typical failure modes (reproduced from [34]), where the number relates to (1) Layer activation, (2) Central fracture, and (3) Non-central fracture.

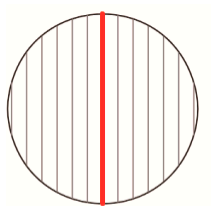

A

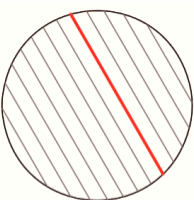

B

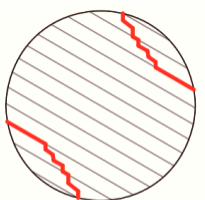

$\mathrm{C}$

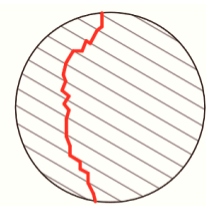

$\mathrm{D}$

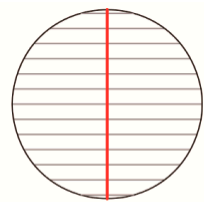

$\mathrm{E}$

Figure 5. Schematic of five kinds of typical failure modes (reproduced from [45]), where the capital letter relates to (A) Pure tensile failure along the bedding; (B) Pure shear failure along the bedding; (C) Mixed-mode failure in the bedding and rock matrix (primarily caused by shear failure); (D) Mixed-mode failure in the bedding and rock matrix (primarily caused by tensile failure); and (E) Pure tensile failure across the rock matrix. 
In fact, the "BtS" usually depends on the failure modes of the Brazilian disc. Therefore, this study analyzed the typical failure photographs of five types of shale rocks, and found that the typical failure can be classified into five categories (see Figure 6): (1) Tensile failure across the weakness planes, (2) Tensile failure along the weakness planes, (3) Shear failure across the weakness planes, (4) Shear failure along the weakness planes, and (5) Mixed failure. In general, the tensile failure along the weakness planes occurs once the weakness plane is parallel to the loading direction; the tensile failure across the weakness planes occurs once the weakness plane is perpendicular to the loading direction; the shear failure along the weakness planes occurs when the weakness plane has a highly-deviated angle; the shear failure across the weakness planes occurs when the weakness plane has a low angle; and the mixed failure often occurs in BDTs. Thus, these five typical failure modes can be utilized to determine the "BtS" of the anisotropic rocks.

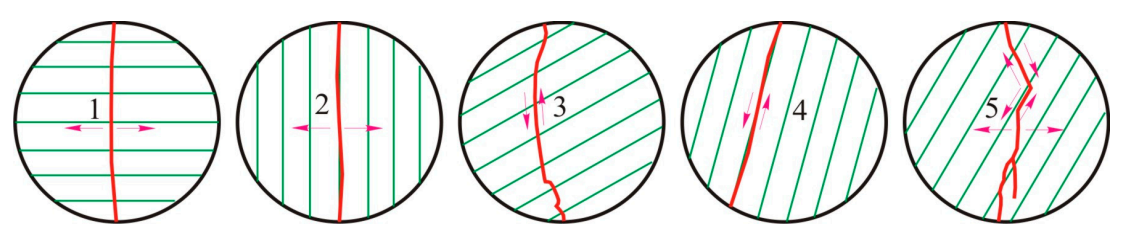

Figure 6. Schematic of five kinds of typical failure modes, where the number relates to (1) Tensile failure across the weakness planes, (2) Tensile failure along the weakness planes, (3) Shear failure across weakness planes, (4) Shear failure along the weakness planes, and (5) Mixed failure.

\section{Modeling of "BtS" for Anisotropic Rocks}

In order to simplify the model, several basic assumptions are made: (1) Anisotropic rock can be simplified as a linear elastic, homogeneous and continuous media; (2) Anisotropic rock obeys the small deformation assumption; (3) The model of BDT can be simplified as the plane-stress problem; (4) The influence of anisotropic modulus is ignored.

\subsection{Stress Distribution}

Regarding the stress distribution on the Brazilian disc, Figure 7 presents the mechanical model of anisotropic rocks under BDT conditions. According to the assumption, the stress state can be calculated by using the isotropic closed-form solution of stress distribution, and the detailed formulas are given in Appendix A (see Equation (A1)). Considering a typical Brazilian disc test which has $D=50 \mathrm{~mm}$, $t=25 \mathrm{~mm}$, and $P=9.0 \mathrm{kN}$. The stress distribution on the disc was calculated by using Equation (A1) and MATLAB software (2014a, The MathWorks, Inc., Natick, MA, USA), and the results are shown in Figure 8. It is clearly understood that the obvious stress concentration occurs around the contact zones of disc with line loading, i.e., the upper and lower zones of the disc. The maximum tensile stress along the $X$ axis is located at the central point of the disc. On this basis, the failure of Brazilian disc can be determined based on the five typical failure modes.
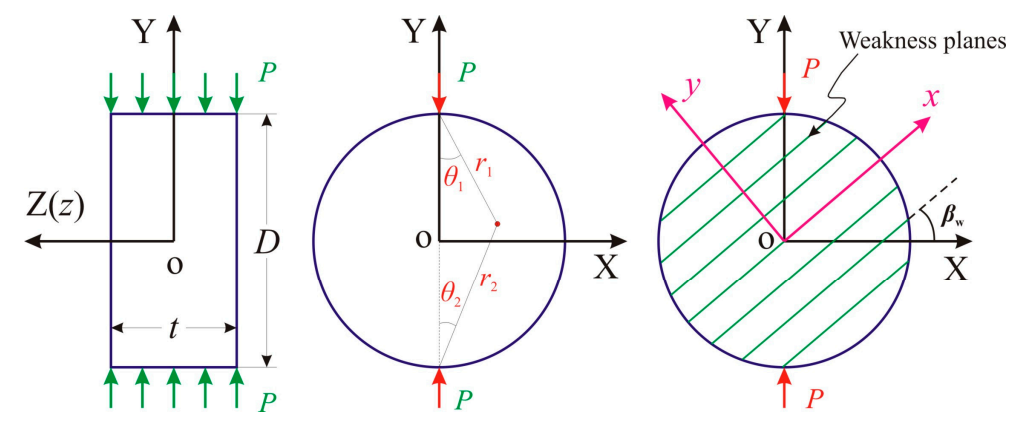

Figure 7. The sketch map of Brazilian disc test for oriented specimen. 

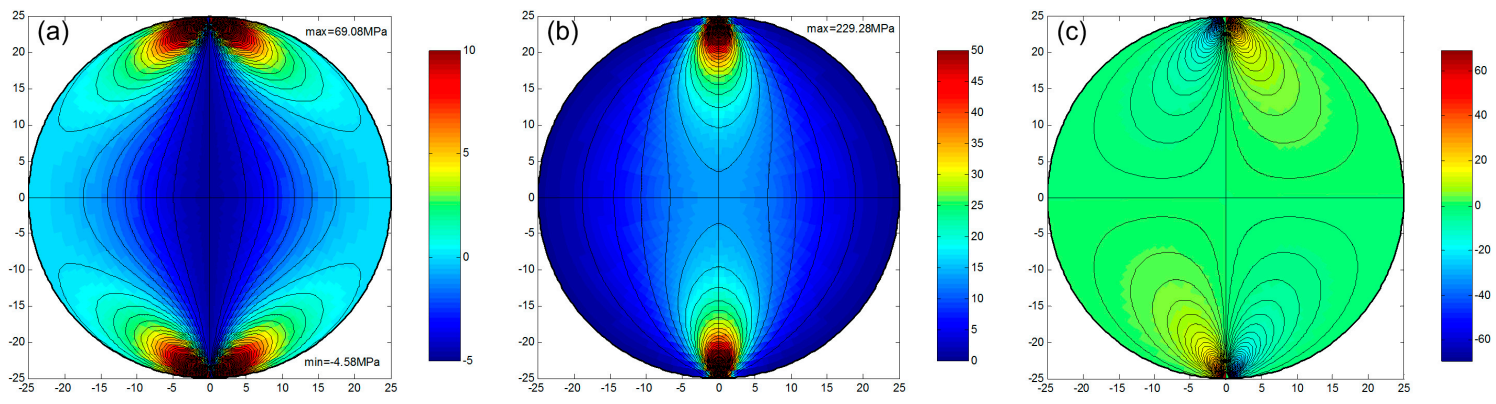

Figure 8. The stress distribution on the Brazilian disc. (a) $\sigma_{X X}(\mathrm{MPa}),(\mathbf{b}) \sigma_{Y Y}(\mathrm{MPa})$, and (c) $\tau_{\mathrm{XY}}(\mathrm{MPa})$.

\subsection{Modeling of "BtS" under Tensile Failure Modes}

The formulas of the anisotropic tensile strength are less developed, due to the difficulty of experimental validation $[11,12,20,21]$. Hobbs investigated the variation of the tensile strength of the laminated rock using Griffith crack theory [62], Nova and Zaninetti proposed an anisotropic tensile failure criterion for schistose rock [63], and Lee and Pietruszczak proposed the tensile equivalent of the SPW theory and a novel 3-D tensile failure function for transversely isotropic rocks [21]. In this paper, the tensile equivalent of the SPW theory was used, which assumes that every physical plane with the exception of weakness plane has identical tensile strength.

According to the stress distribution on the Brazilian disc, as shown in Figure 8a, the maximum tensile stress occurs at the central point of the disc. The stress state of the central region can be simplified as an element, as shown in Figure 9. This figure presents three typical cases of oriented Brazilian disc, and no confirmed pressure load on the element under BDT conditions (i.e., $\sigma_{Y Y}=\tau_{X Y}=0$ ). Therefore, for the central element, the tensile stress that load on the surface of weakness planes can be expressed as:

$$
\sigma_{\mathrm{nw}}=\sigma_{\mathrm{XX}} \sin ^{2} \beta_{\mathrm{w}} \quad(\mathrm{X}=\mathrm{Y}=0)
$$

Then, once the normal stress load on the surface of weakness planes reaches a critical value $T_{\mathrm{w}}$, the tensile failure will occur, and the tensile strength criterion can be expressed as:

$$
\sigma_{\mathrm{nw}}=\sigma_{\mathrm{XX}} \sin ^{2} \beta_{\mathrm{w}}=-T_{\mathrm{w}}
$$

Substituting Equation (A2) into Equation (3), we can obtain:

$$
T\left(\beta_{\mathrm{w}}\right)=\left|\sigma_{\mathrm{XX}}\right|=\frac{2 P}{\pi D t}=\frac{T_{\mathrm{w}}}{\sin ^{2} \beta_{\mathrm{w}}}
$$

Equation (4) holds true for angle $\beta_{\mathrm{w}}$ less than a critical value $\beta^{*}{ }_{\mathrm{w}}$. For $0^{\circ} \leq \beta_{\mathrm{w}} \leq \beta^{*}{ }_{\mathrm{w}}$, the tensile strength is equal to the tensile strength of intact rock $T_{\mathrm{m}}$ and the failure plane is perpendicular to the loading direction [21], as shown in Figure 9. Then, substituting the tensile strength of intact rock $T_{\mathrm{m}}$ into Equation (4):

$$
\frac{T_{\mathrm{w}}}{\sin ^{2} \beta_{\mathrm{w}}}=T_{\mathrm{m}}
$$

The critical value $\beta^{*}{ }_{\mathrm{w}}$ therefore can be expressed as:

$$
\beta_{\mathrm{w}}^{*}=\sin ^{-1} \sqrt{\frac{T_{\mathrm{w}}}{T_{\mathrm{m}}}}
$$


Therefore, the failure criterion under BDT conditions can be rewritten as:

$$
\begin{cases}B t S_{1}\left(\beta_{\mathrm{w}}\right)=T_{\mathrm{m}} & 0^{\circ} \leq \beta_{\mathrm{w}} \leq \beta_{\mathrm{w}}^{*} \\ \operatorname{BtS} S_{2}\left(\beta_{\mathrm{w}}\right)=\frac{T_{\mathrm{w}}}{\sin ^{2} \beta_{\mathrm{w}}} & \beta_{\mathrm{w}}^{*} \leq \beta_{\mathrm{w}} \leq 90^{\circ}\end{cases}
$$

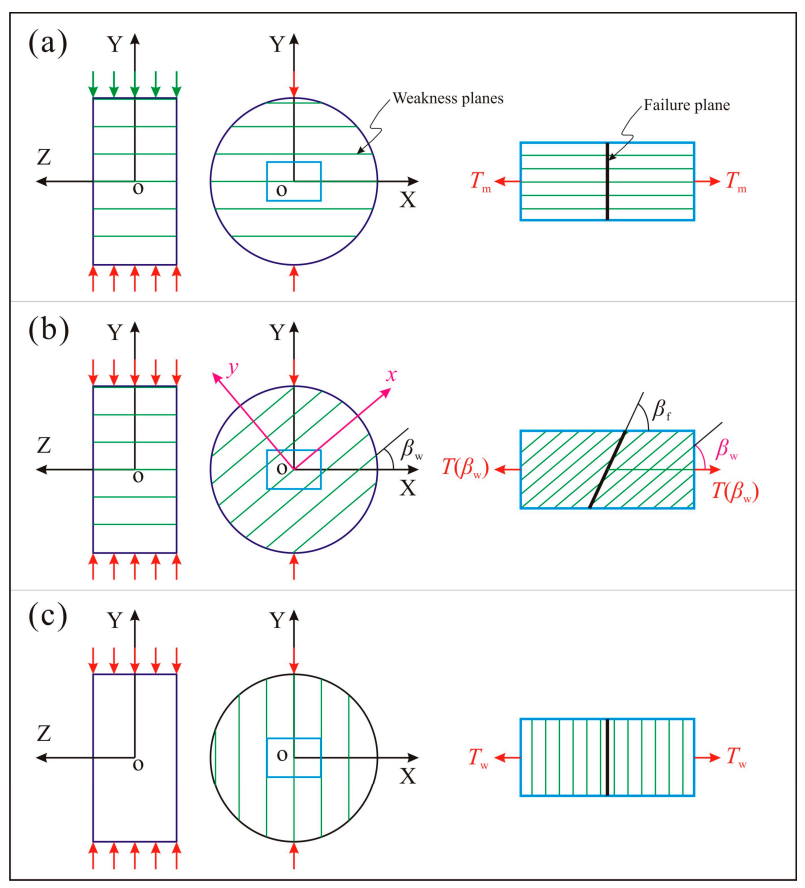

Figure 9. The tensile strength of oriented Brazilian disc: (a) $\beta_{\mathrm{w}}=0^{\circ} ;$ (b) $0^{\circ}<\beta_{\mathrm{w}}<90^{\circ}$, and (c) $\beta_{\mathrm{w}}=90^{\circ}$. Reproduced with permission from [11], Journal of Petroleum Science and Engineering; Published by Elsevier B.V., 2017.

\subsection{Modeling of "BtS" under Shear Failure Modes}

\subsubsection{Anisotropic Shear Criterion}

In the early 1960s, Jaeger proposed the SPW theory which tried to characterize the anisotropic shear strength of anisotropic rocks [1,14,15]. A larger number of failure criteria for anisotropic rocks have been developed [64]. To date, Jaeger's SPW theory has played a very important role in rock engineering. Therefore, we still use the Jaeger's SPW theory to describe the anisotropic shear strength of anisotropic rocks. As shown in Figure 10, if there is a group of weakness planes in the anisotropic rock, then the failure criterion can be expressed as [1]:

$$
\begin{cases}\tau_{0}=c_{0}+\sigma_{\mathrm{n} 0} \tan \varphi_{0} & \text { failure across the weak planes } \\ \tau_{\mathrm{w}}=c_{\mathrm{w}}+\sigma_{\mathrm{nw}} \tan \varphi_{\mathrm{w}} & \text { failure along the weak planes }\end{cases}
$$

Equation (8) can also be rewritten using the principal stresses [1]:

$$
\begin{cases}\sigma_{1}=\frac{1+\sin \varphi_{0}}{1-\sin \varphi_{0}} \sigma_{3}+\frac{2 c_{0} \cos \varphi_{0}}{1-\sin \varphi_{0}} & \left(\beta<\beta_{1} \text { or } \beta>\beta_{1}\right) \\ \sigma_{1}=\sigma_{3}+\frac{2\left(c_{\mathrm{w}}+\sigma_{3} \tan \varphi_{\mathrm{w}}\right)}{\left(1-\tan \varphi_{\mathrm{w}} \cot \beta\right) \sin 2 \beta} & \left(\beta_{1} \leq \beta \leq \beta_{2}\right)\end{cases}
$$


where $\beta_{1}$ and $\beta_{2}$ are given as [1]:

$$
\left\{\begin{array}{l}
\beta_{1}=\frac{\varphi_{\mathrm{w}}}{2}+\frac{1}{2} \arcsin \left[\frac{\left(\sigma_{1}+\sigma_{3}+2 c_{\mathrm{w}} \cot \varphi_{\mathrm{w}}\right) \sin \varphi_{\mathrm{w}}}{\sigma_{1}-\sigma_{3}}\right] \\
\beta_{2}=\frac{\pi}{2}+\frac{\varphi_{\mathrm{w}}}{2}-\frac{1}{2} \arcsin \left[\frac{\left(\sigma_{1}+\sigma_{3}+2 c_{w} \cot \varphi_{\mathrm{w}}\right) \sin \varphi_{\mathrm{w}}}{\sigma_{1}-\sigma_{3}}\right]
\end{array}\right.
$$

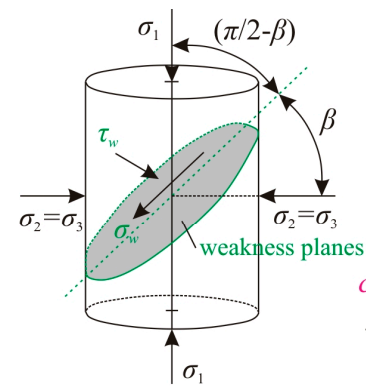

(a)

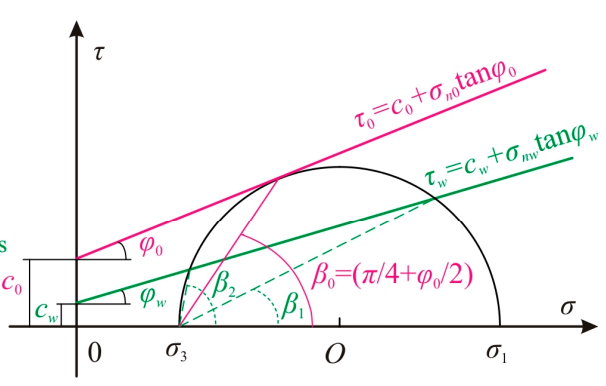

(b)

Figure 10. Schematic of strength analysis for anisotropic rocks with a single group of weakness planes (reproduced from [65]). (a) Stress state of a tri-axial test, and (b) Schematic map of strength envelope.

As shown in Figure 10 and Equation (10), the shear strength of anisotropic rock is controlled by both weakness planes and rock matrix. If $\beta_{1} \leq \beta \leq \beta_{2}$, the shear strength of anisotropic rock is controlled by weakness planes, i.e., the failure mode belongs shear failure along the weakness planes; while if $0^{\circ} \leq \beta \leq \beta_{1}$ or $\beta_{2} \leq \beta \leq 90^{\circ}$, the shear strength of anisotropic rock is controlled by intact rock, i.e., the failure mode belongs shear failure of intact rock.

\subsubsection{Solution Method of "BtS" under Shear Failure Modes}

Combining Equations (A1), (9) and (10), the failure of the disc that was induced by shear along or across the weakness planes can be determined. However, due to the impacts of the stress distribution on the disc being involved, the analytical formulas are difficult to obtain. Thus, a numerical method was developed to calculate these equations for each point on the disc. The main processes of this method can be summarized as shown in Figure 11. To simplify the calculated processes, this study utilized the original form of the shear criterion of the weakness planes (see Equation (8)), and defined two functions to determine the shear failure. These two functions can be expressed as:

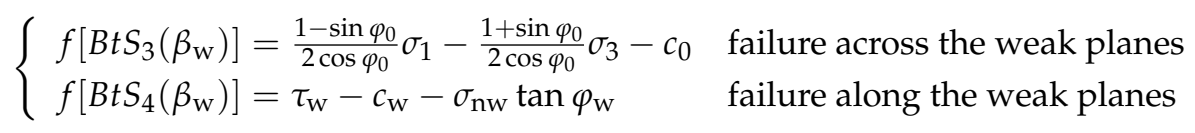

where $\sigma_{1}, \sigma_{3}, \sigma_{\mathrm{nw}}$ and $\tau_{\mathrm{w}}$ are given as:

$$
\left\{\begin{array}{c}
\left\{\begin{array}{c}
\sigma_{1}=0.5\left(\sigma_{\mathrm{XX}}+\sigma_{\mathrm{YY}}\right)+\left\{\left[0.5\left(\sigma_{\mathrm{XX}}-\sigma_{\mathrm{YY}}\right)\right]^{2}+\tau_{\mathrm{XY}}^{2}\right\}^{\frac{1}{2}} \\
\sigma_{3}=0.5\left(\sigma_{\mathrm{XX}}+\sigma_{\mathrm{YY}}\right)-\left\{\left[0.5\left(\sigma_{\mathrm{XX}}-\sigma_{\mathrm{YY}}\right)\right]^{2}+\tau_{\mathrm{X} Y}^{2}\right\}^{\frac{1}{2}}
\end{array}\right. \\
\left\{\begin{array}{c}
\sigma_{\mathrm{nW}}=\sigma_{\mathrm{XX}} \sin ^{2} \beta_{\mathrm{W}}+\sigma_{\mathrm{YY}} \cos ^{2} \beta_{\mathrm{W}}-2 \tau_{\mathrm{X} Y} \sin \beta_{\mathrm{W}} \cos \beta_{\mathrm{W}} \\
\tau_{\mathrm{w}}=\left(\sigma_{\mathrm{YY}}-\sigma_{\mathrm{XX}}\right) \sin \beta_{\mathrm{W}} \cos \beta_{\mathrm{w}}+\tau_{\mathrm{XY}}\left(\cos ^{2} \beta_{\mathrm{W}}-\sin ^{2} \beta_{\mathrm{W}}\right)
\end{array}\right.
\end{array}\right.
$$

If the additional cohesion $f\left[B t S_{3}\left(\beta_{\mathrm{w}}\right)\right]$ equals or exceeds 0 , shear failure occurs across the weakness planes, and the relevant "BtS" can be defined as $B t S_{3}\left(\beta_{\mathrm{w}}\right)$. Similarly, if the additional cohesion $f\left[B t S_{4}\left(\beta_{\mathrm{W}}\right)\right]$ equals or exceeds 0 , shear failure occurs along the weakness planes, and the relevant "BtS" can be defined as $B t S_{4}\left(\beta_{\mathrm{W}}\right)$. 


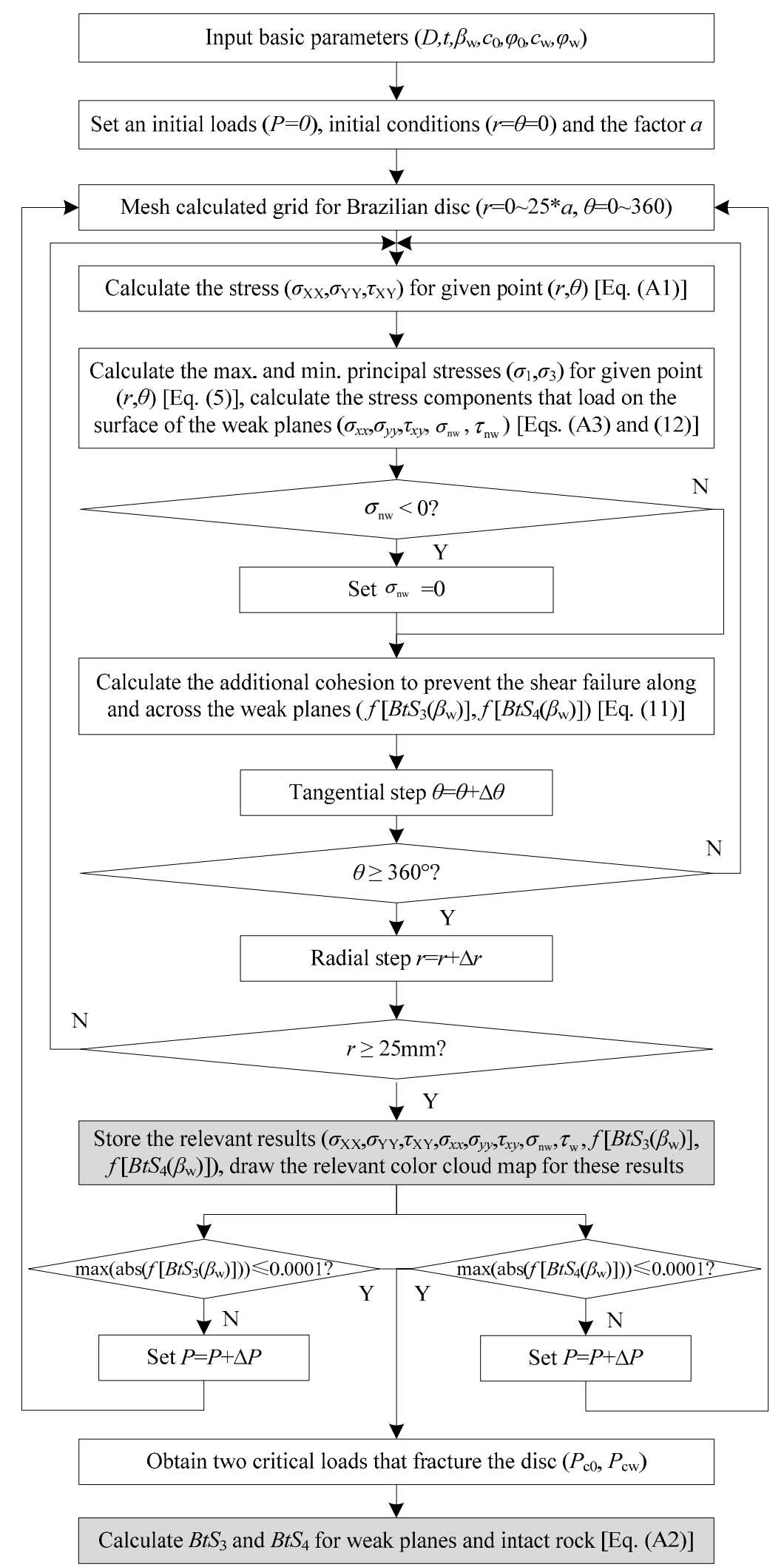

Figure 11. The solution flowchart of "BtS" under shear failure modes. 
In addition, in order to involve the impacts of stress distribution on the disc in this method, this study defined a radial ratio (a) to select the solution domain on the disc, and the solution domain on the disc locates in the following range:

$$
r \leq \frac{a}{2} D
$$

When $a=0$, the solution domain contains only the central point; when $a=1$, the solution domain contains the entire disc. The reason why we define the radial ratio of the solution domain on the disc is due to finding that the predicted " $\mathrm{BtS}$ " is too high when the solution domain contains just the central point, and it is too low when the solution domain contains the entire disc. This is due to the isotropic closed-form solution of the stress distribution on the Brazilian disc not perfectly aligning with the realities of the situation. Therefore, the radial ratio was defined to determine the proper domain based on the contrast between the predicted and experimental results. In addition, the following situations need to be stated: (1) The solution flowchart can only solve the "BtS" under a given $\beta_{\mathrm{w}}$. (2) The stress distribution, the principal stress, and the stress components that load on the surface of the weakness plane can be drawn using the color cloud map for a given angle $\beta_{\mathrm{w}}$ and loads $P$. (3) The additional failure function of $f\left[B t S_{3}\left(\beta_{\mathrm{w}}\right)\right]$ and $f\left[B t S_{4}\left(\beta_{\mathrm{w}}\right)\right]$ (i.e., the failure patterns of the Brazilian disc) can also be drawn using the color cloud map can be drawn using the color cloud map.

\subsection{Modeling of Integrated "BtS" for Anisotropic Rocks}

The criteria of five typical failure modes in Figure 6 can be sorted as Table 3. When the "BtS" under each condition is calculated, the final or integrated "BtS" should be the lowest "BtS" of each condition:

$$
B t S\left(\beta_{\mathrm{w}}\right)=\min \left\{B t S_{1}\left(\beta_{\mathrm{w}}\right), B t S_{2}\left(\beta_{\mathrm{w}}\right), B t S_{3}\left(\beta_{\mathrm{w}}\right), B t S_{4}\left(\beta_{\mathrm{w}}\right)\right\}
$$

\begin{tabular}{|c|c|c|c|c|}
\hline No. & Failure Type & Calculated BTS & Formula & Failure Pattern \\
\hline 1 & $\begin{array}{l}\text { Tensile failure } \\
\text { across weakness } \\
\text { planes }\end{array}$ & $B t S_{1}\left(\beta_{\mathrm{W}}\right)$ & $\begin{array}{l}\operatorname{BtS}\left(\beta_{\mathrm{w}}\right)=T_{\mathrm{m}} \\
\text { if } 0^{\circ} \leq \beta_{\mathrm{w}} \leq \beta_{\mathrm{w}}^{*}\end{array}$ & \\
\hline 2 & $\begin{array}{l}\text { Tensile failure } \\
\text { along weakness } \\
\text { planes }\end{array}$ & $B t S_{2}\left(\beta_{\mathrm{w}}\right)$ & $\begin{array}{l}\operatorname{BtS}\left(\beta_{\mathrm{w}}\right)=\frac{T_{\mathrm{w}}}{\sin ^{2} \beta_{\mathrm{w}}} \\
\text { if } \beta_{\mathrm{w}}^{*} \leq \beta_{\mathrm{w}} \leq 90^{\circ}\end{array}$ & \\
\hline 3 & $\begin{array}{c}\text { Shear failure } \\
\text { across weakness } \\
\text { planes }\end{array}$ & $B t S_{3}\left(\beta_{\mathrm{w}}\right)$ & $\begin{array}{l}\tau_{0}=c_{0}+\sigma_{\mathrm{n} 0} \tan \varphi_{0} \\
\text { if } \beta<\beta_{1} \text { or } \beta>\beta_{2}\end{array}$ & \\
\hline 4 & $\begin{array}{l}\text { Shear failure } \\
\text { along weakness } \\
\text { planes }\end{array}$ & $B t S_{4}\left(\beta_{\mathrm{w}}\right)$ & $\begin{array}{l}\tau_{\mathrm{w}}=c_{\mathrm{w}}+\sigma_{\mathrm{nW}} \tan \varphi_{\mathrm{w}} \\
\text { if } \beta_{1} \leq \beta \leq \beta_{2}\end{array}$ & \\
\hline 5 & Mixed failure & $B t S_{5}\left(\beta_{\mathrm{w}}\right)$ & $\operatorname{BtS}\left(\beta_{\mathrm{w}}\right)=\min \left\{\begin{array}{l}B t S_{1}\left(\beta_{\mathrm{w}}\right), B t S_{2}\left(\beta_{\mathrm{w}}\right), \\
B t S_{3}\left(\beta_{\mathrm{w}}\right), B t S_{4}\left(\beta_{\mathrm{w}}\right)\end{array}\right\}$ & \\
\hline
\end{tabular}

Table 3. The integrated failure criteria for layered rocks. 
To calculate the integrated "BtS" for anisotropic, the main steps can be concluded as follows: (1) Calculate the $B t S_{1}\left(\beta_{\mathrm{W}}\right)$ and $B t S_{2}\left(\beta_{\mathrm{W}}\right)$ by using Equation (7) to obtain the "BtS" under tensile failure modes; (2) Set the radial ratio from 0 to 1 to calculate the "BtS" under shear failure modes, and calculate the $B t S_{3}\left(\beta_{\mathrm{w}}\right)$ and $B t S_{4}\left(\beta_{\mathrm{w}}\right)$ by using Equation (11) to obtain the "BtS" under shear failure modes; (3) Calculate the integrated $B t S\left(\beta_{\mathrm{w}}\right)$ for anisotropic rocks by using Equation (14).

\section{Results and Discussions}

\subsection{Model Validation for Longmaxi Shale-I}

In order to demonstrate the performance of the "BtS" modeling, the BDT results of Longmaxi Shale-I published by Yang et al. (2015) [47] were utilized, and the test results are listed in Table 4. The other basic parameters are as follows [47]: $c_{0}=16.175 \mathrm{MPa}, c_{\mathrm{W}}=8.980 \mathrm{MPa}, \varphi_{0}=36.222^{\circ}$, $\varphi_{\mathrm{w}}=33.862^{\circ}, T_{\mathrm{m}}=6.606 \mathrm{MPa}$, and $T_{\mathrm{w}}=3.470 \mathrm{MPa}$.

Table 4. The BtS versus $\beta_{\mathrm{w}}$ of Longmaxi Shale-I (After Yang et al., 2015 [47]).

\begin{tabular}{cccccccc}
\hline \multirow{2}{*}{ No. } & \multicolumn{7}{c}{ BtS Versus $\boldsymbol{\beta}_{\mathbf{w}} \mathbf{( M P a )}$} \\
\cline { 2 - 8 } & $\mathbf{0}^{\circ}$ & $\mathbf{1 5}^{\circ}$ & $\mathbf{3 0 ^ { \circ }}$ & $\mathbf{4 5 ^ { \circ }}$ & $\mathbf{6 0}^{\circ}$ & $\mathbf{7 5}^{\circ}$ & $\mathbf{9 0}^{\circ}$ \\
\hline 1 & 5.546 & 5.457 & 4.75 & 5.15 & 3.329 & 2.554 & 4.258 \\
2 & 7.027 & 6.423 & 6.088 & 3.517 & 3.94 & 3.177 & 3.112 \\
3 & 7.254 & 6.705 & 5.624 & 3.475 & 3.338 & 4.666 & 3.053 \\
Mean & 6.609 & 6.195 & 5.587 & 4.047 & 3.535 & 3.465 & 3.474 \\
Predicted BtS & 6.606 & 6.606 & 5.371 & 3.814 & 3.394 & 3.633 & 3.470 \\
Error & $0.05 \%$ & $6.55 \%$ & $3.92 \%$ & $5.83 \%$ & $4.13 \%$ & $4.70 \%$ & $0.00 \%$ \\
\hline
\end{tabular}

\subsubsection{Calculation of $B t S_{1}\left(\beta_{\mathrm{w}}\right)$ and $B t S_{2}\left(\beta_{\mathrm{w}}\right)$}

Figure 12 displays the tensile strength of the Brazilian disc for both isotropic and anisotropic rocks. When $0^{\circ} \leq \beta_{\mathrm{w}} \leq 46^{\circ}$, the angle $\beta_{\mathrm{w}}$ has no influence on the "BtS", and the Brazilian disc experiences tensile failure across the weakness planes; when $46^{\circ} \leq \beta_{\mathrm{W}} \leq 90^{\circ}$, the angle $\beta_{\mathrm{W}}$ has a significant influence on the "BtS", the "BtS" decrease with $\beta_{\mathrm{w}}$, and the Brazilian disc experiences tensile failure along the weakness plane. In addition, the anisotropy of tensile strength is controlled by the ratio of $T_{\mathrm{m}}$ to $T_{\mathrm{w}} \cdot T_{\mathrm{m}} / T_{\mathrm{w}}=1$ represents an isotropic rock, the anisotropic degree and the critical value $\beta_{\mathrm{w}}^{*}$ increase as the increase in the ratio of $T_{\mathrm{m}}$ to $T_{\mathrm{W}}$, and the tensile failure along the weak planes also occurs more easily.

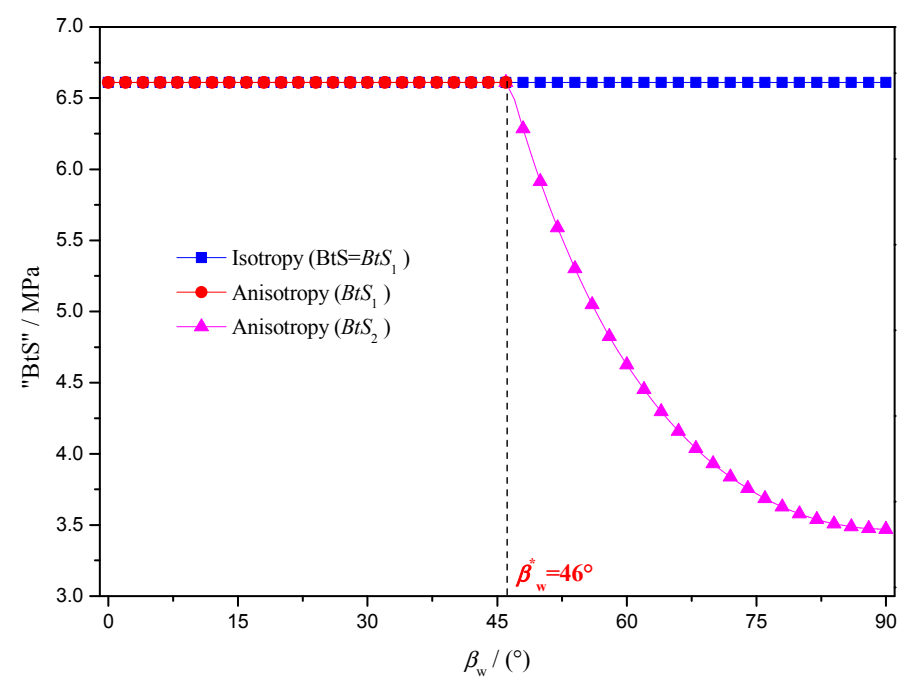

Figure 12. The "BtS" of Longmaxi Shale-I under tensile failure modes. 


\subsubsection{Calculation of $B t S_{3}\left(\beta_{\mathrm{w}}\right)$ and $B t S_{4}\left(\beta_{\mathrm{w}}\right)$}

Figure 13 displays the "BtS" of a Brazilian disc versus $\beta_{\mathrm{w}}$ and radial ratio (a) under shear failure modes for Longmaxi Shale-I. It reveals the characteristics of "BtS" that are controlled by shear failure. The radial ratio and angle $\beta_{\mathrm{w}}$ has a significant influence on the "BtS". The "BtS" decreases with the radial ratio, and the "BtS" reaches its maximum magnitude when $a \rightarrow 0$, while the "BtS" reaches its minimum magnitude when $a \rightarrow 1$. The "BtS" of shear failure across the weakness planes is the upper boundary, and the lower boundary should be $\beta_{\mathrm{w}}=60^{\circ}$. Once the "BtS" of shear failure along the weakness planes reaches the upper boundary, the shear failure is controlled by the strength of intact rock. If the "BtS" is lower than the upper boundary, the shear failure of the Brazilian disc should belong to the shear failure along the weakness planes. When the radial ratio is a constant, the " $\mathrm{BtS}$ " shows a "U" shaped curve. The geometry of the " $U$ " shaped curve is similar to the strength curve of Jaeger's SPW theory. The results revealed that the "BtS" is controlled by the shear failure both across and along the weakness planes.

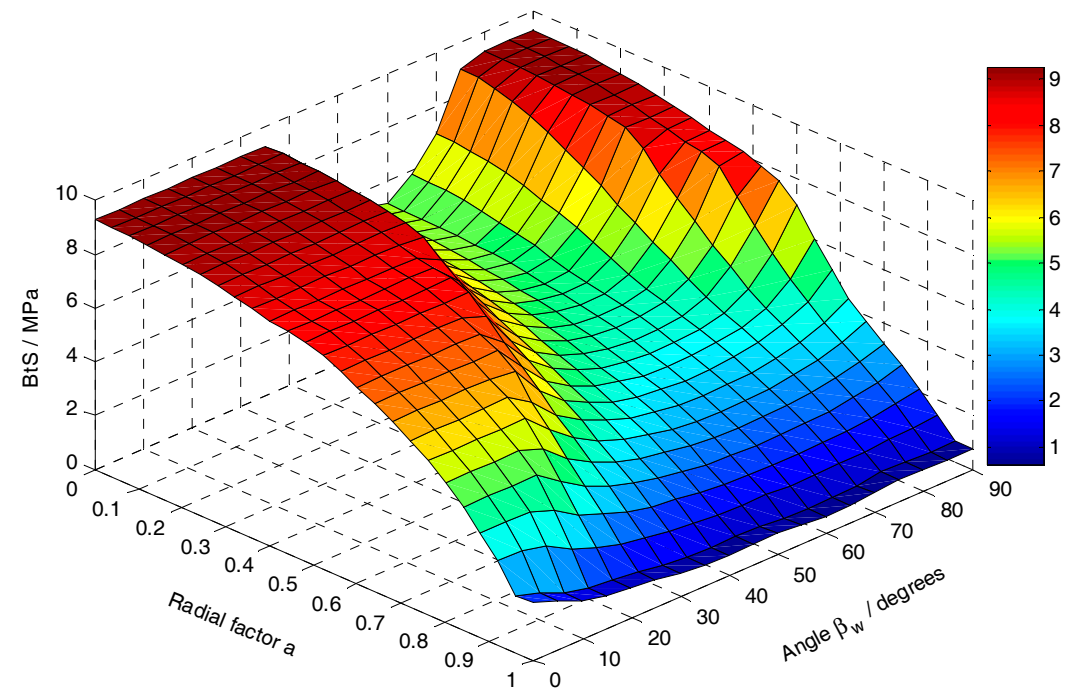

Figure 13. The 3D surface of "BtS" versus $\beta_{\mathrm{w}}$ and radial ratio under shear failure modes.

\subsubsection{Comparison of Integrated "BtS" with Test Results}

Figure $14 \mathrm{a}$ shows how to obtain the integrated "BtS" by combining the $B t S_{1}\left(\beta_{\mathrm{w}}\right), B t S_{2}\left(\beta_{\mathrm{w}}\right)$, $B t S_{3}\left(\beta_{\mathrm{w}}\right)$ and $B t S_{4}\left(\beta_{\mathrm{W}}\right)$ for Longmaxi Shale-I, i.e., the integrated "BtS" should be the lowest "BtS" of the four types of failure modes. The green dot line displays the "BtS" under tensile failure modes, the blue dot line displays the "BtS" under shear failure modes, and the red solid line displays the integrated "BtS" for a given radial ratio $(a=0.4)$. It is clearly noticed that the failure of anisotropic rock under the BDT condition is controlled by (1) tensile failure of the intact rock when $0^{\circ} \leq \beta_{\mathrm{w}} \leq 39^{\circ}$, (2) shear failure along the weakness planes when $39^{\circ} \leq \beta_{\mathrm{w}} \leq 60^{\circ}$, and (3) tensile failure along the weakness planes when $60^{\circ} \leq \beta_{\mathrm{w}} \leq 90^{\circ}$. 

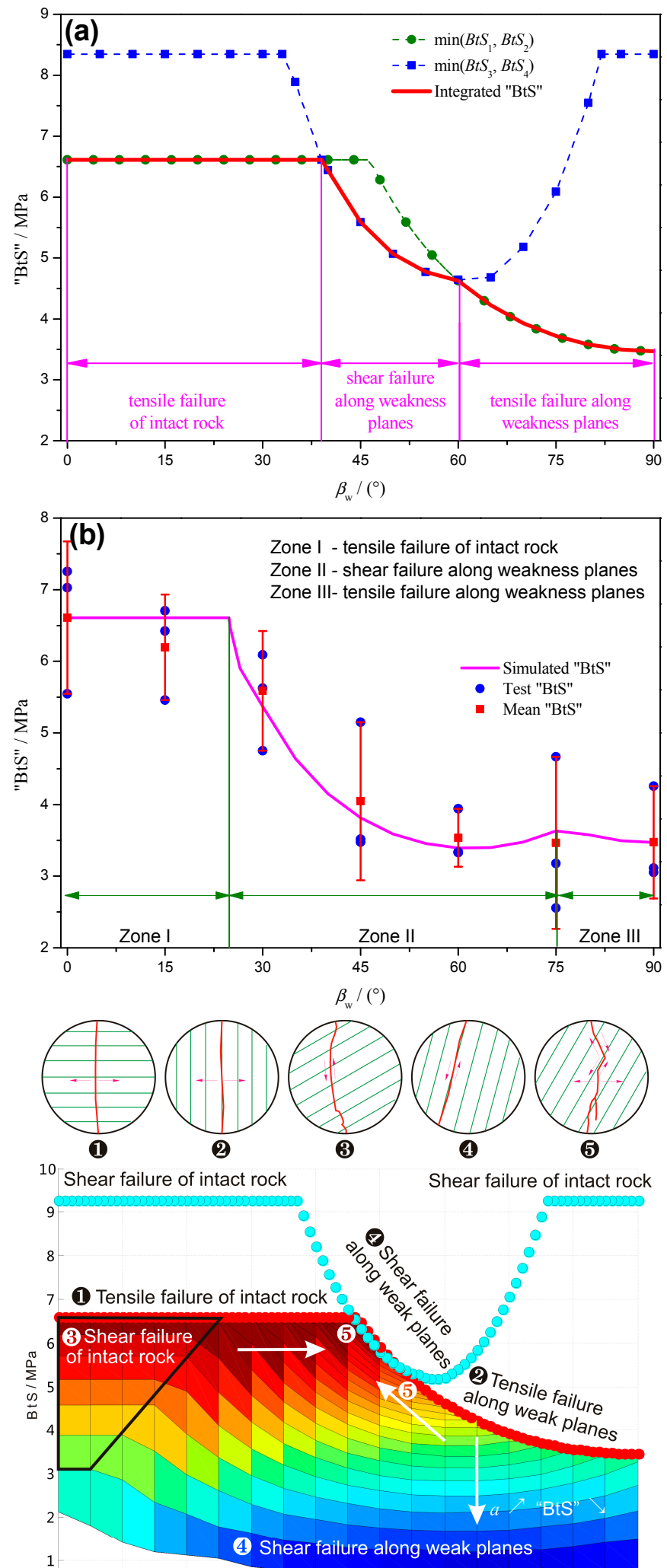

(c)

$\begin{array}{llllllllll}0 & 10 & 20 & 30 & 40 & 50 & 60 & 70 & 80 & 90\end{array}$

Figure 14. The contrast between the predicted and test "BtS" for Longmaxi Shale-I. (a) The integrated "BtS" versus $\beta_{\mathrm{w}}(a=0.4)$; (b) The contrast between predicted and test results for Longmaxi Shale-I $(a=0.68)$; and (c) The potential range of integrated " $\mathrm{BtS}$ ". 
For Longmaxi Shale-I, when the radial ratio equals 0.68 , the integrated $B t S\left(\beta_{\mathrm{w}}\right)$ is the greatest with the average of the test results, as shown in Figure 14b. The maximum deviation from the test results is $\sim 6.55 \%$, as shown in Table 4 . The failure modes of Longmaxi Shale-I can be concluded as follows: (1) When $0^{\circ} \leq \beta_{\mathrm{w}} \leq 24^{\circ}$, i.e., Zone I in Figure 14b, the Brazilian disc shows tensile failure of rock matrix or intact rock; (2) When $24^{\circ} \leq \beta_{\mathrm{w}} \leq 76^{\circ}$, i.e., Zone II in Figure $14 \mathrm{~b}$, the disc shows shear failure along the weakness planes; (3) When $76^{\circ} \leq \beta_{\mathrm{w}} \leq 90^{\circ}$, i.e., Zone III in Figure $14 \mathrm{~b}$, the disc shows tensile failure along the weakness planes; (4) In the connected regions, i.e., $\beta_{\mathrm{W}}$ is close to $24^{\circ}$ or $76^{\circ}$, mixed failure usually occurs. Therefore, the present method is reasonable and accurate for predicting the "BtS" under the BDT conditions.

In addition, due to the radial ratio also having a significant impact on "BtS", for an arbitrary radial ratio, the potential range of the integrated "BtS" for Longmaxi Shale-I is shown in Figure 14c. It is clearly seen that the maximum magnitude of the integrated "BtS" depends on the tensile failure across and along the weakness planes, and the shear failure along the weakness planes; while the minimum magnitude of the integrated "BtS" just depends on the shear failure along the weakness planes. Meanwhile, the value of the radial ratio is also very important for the integrated "BtS", where the integrated " $\mathrm{BtS}$ " decreases with the radial ratio. In general, the recommended value of the radial ratio is approximately $0.60-0.80$.

\subsubsection{Comparison of Failure Modes between Simulated and Test Results}

In order to further investigate the influence of weakness planes on the failure of a Brazilian disc, the failure patterns were simulated for oriented Brazilian discs of Longmaxi Shale-I, and the simulated results are shown in Figure 15. In these figures, the failure patterns of four typical modes were filled with four colors, where the number of colored bars relates to (1) Tensile failure across weakness planes, (2) Tensile failure along weakness planes, (3) Shear failure along weakness planes, and (4) Shear failure across weakness planes. These figures indicate the potential failure zones when the load reaches its peak. We can contrast the simulated results with the test results of Longmaxi Shale-I [55], see Figure 3a, and the simulated failure patterns appear to be consistent with the test results. It is clearly found that (1) The failure zones of a Brazilian disc usually occur near the top and bottom of the contact zones; (2) Only three cases can cause a central tensile fracture, i.e., $\beta_{\mathrm{W}}=0^{\circ}, 15^{\circ}$ and $90^{\circ}$, as shown in Figure 13a,b,g; (3) When $30^{\circ} \leq \beta_{\mathrm{w}} \leq 75^{\circ}$, the Brazilian disc can only experience shear failure along the weakness planes. The simulated results of failure patterns are consistent with the predicted "BtS", and also demonstrated the performance of the proposed method. 


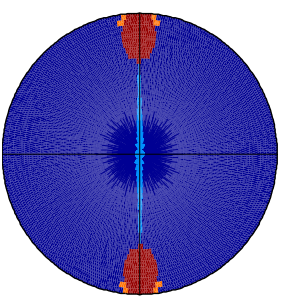

(a)

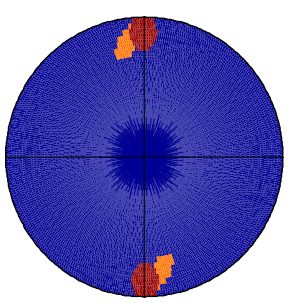

(c)

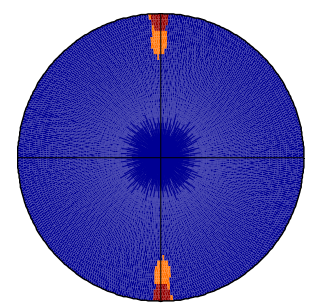

(e)

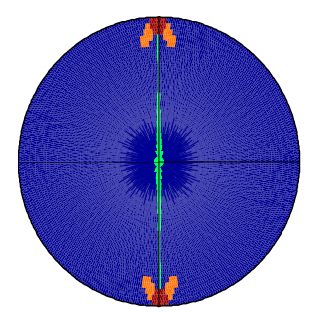

(g)

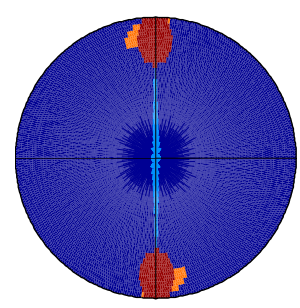

(b)

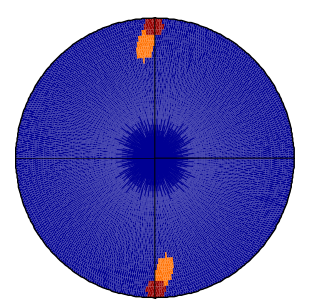

(d)

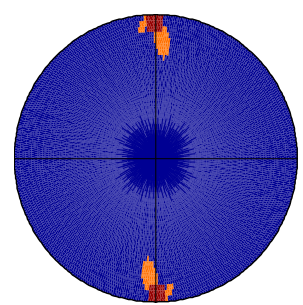

(f)

1-Tensile failure across weakness planes 2-Tensile failure along weakness planes 3-Shear failure along weakness planes 4-Shear failure across weakness planes

Figure 15. The failure patterns of Brazilian disc of Longmaxi Shale-I. (a) $\beta_{\mathrm{W}}=0^{\circ}$; (b) $\beta_{\mathrm{W}}=15^{\circ}$; (c) $\beta_{\mathrm{w}}=30^{\circ} ;$ (d) $\beta_{\mathrm{w}}=45^{\circ} ;$ (e) $\beta_{\mathrm{w}}=60^{\circ}$; (f) $\beta_{\mathrm{w}}=75^{\circ} ;$ (g) $\beta_{\mathrm{w}}=90^{\circ}$.

\subsection{Model Generalization and Further Validation}

\subsubsection{Model Generalization}

We also occasionally encountered some more complex cases of the anisotropic rocks containing multi-groups of weakness planes. In order to describe the shear strength of these cases, the superposition principle was useful. As shown in Figure 16, for weakness plane No. 1 and arbitrary No. $i$, the failure criterion can be rewritten as [65]:

$$
\begin{cases}\tau_{0}=c_{0}+\sigma_{\mathrm{n} 0} \tan \varphi_{0} & \text { failure across all of the weak planes } \\ \tau_{\mathrm{w}}^{(1)}=c_{\mathrm{W}}^{(1)}+\sigma_{\mathrm{nw}}^{(1)} \tan \varphi_{\mathrm{W}}^{(1)} & \text { slipping along the weak planes No. } 1 \\ \tau_{\mathrm{w}}^{(i)}=c_{\mathrm{W}}^{(i)}+\sigma_{\mathrm{nw}}^{(i)} \tan \varphi_{\mathrm{w}}^{(i)} & \text { slipping along the weak planes No. } i\end{cases}
$$




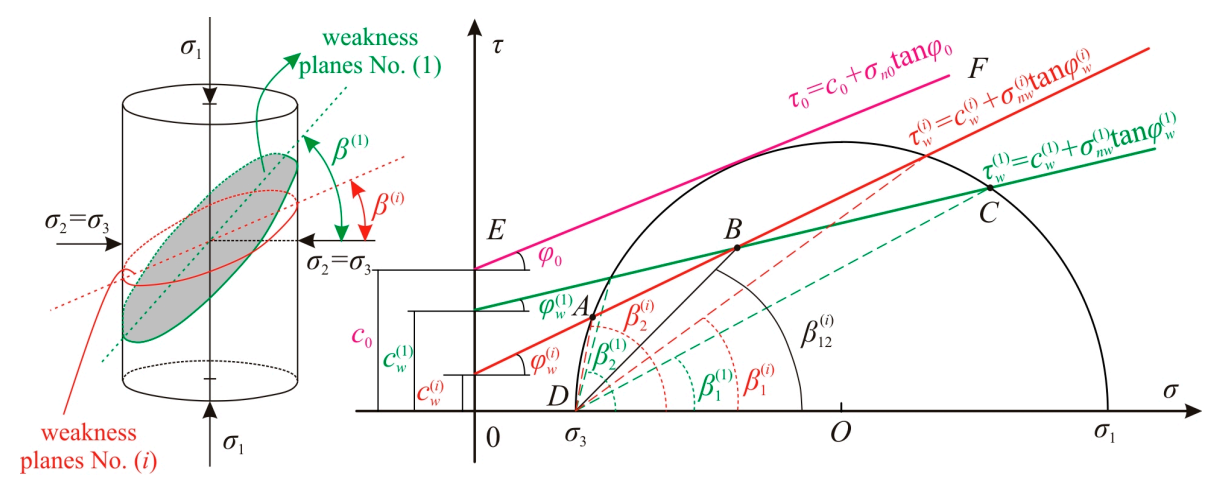

(a)

(b)

Figure 16. Schematic of strength analysis for anisotropic rocks with multi-groups of weakness planes (reproduced from [65]). (a) Loads analysis of tri-axial test, and (b) The schematic map of strength envelope.

Equation (15) can also be rewritten using the principal stresses [65]:

$$
\left\{\begin{array}{cc}
\sigma_{1}=\frac{1+\sin \varphi_{0}}{1-\sin \varphi_{0}} \sigma_{3}+\frac{2 c_{0} \cos \varphi_{0}}{1-\sin \varphi_{0}} & \left(\beta<\beta_{1}^{(1)} \text { or } \beta>\beta_{2}^{(i)}\right) \\
\sigma_{1}=\sigma_{3}+\frac{2\left(c_{\mathrm{w}}^{(1)}+\sigma_{3} \tan \varphi_{\mathrm{w}}^{(1)}\right)}{\left(1-\tan \varphi_{\mathrm{w}}^{(1)} \cot \beta\right) \sin 2 \beta} & \left(\beta_{1}^{(1)} \leq \beta \leq \beta_{12}^{(i)}\right) \\
\sigma_{1}=\sigma_{3}+\frac{2\left(c_{\mathrm{w}}^{(i)}+\sigma_{3} \tan \varphi_{\mathrm{w}}^{(i)}\right)}{\left(1-\tan \varphi_{\mathrm{w}}^{(i)} \cot \beta\right) \sin 2 \beta} & \left(\beta_{12}^{(i)} \leq \beta \leq \beta_{2}^{(i)}\right)
\end{array}\right.
$$

The strength envelope curve of anisotropic rock with multi-groups of weakness planes can be replaced by line $A B C$. Meanwhile, the strength of anisotropic rock depends on both curves $A B C$ and EF [65]. Then, the typical compressive strength of anisotropic rock will be weakened, i.e., the influence of the group numbers of weakness planes on compressive strength is very significant. Thus, the influence of multi-groups of weakness planes on "BtS" also cannot be ignored.

If the anisotropic rocks contain multi-groups of weakness planes, we can calculate the relevant "BtS" for each group of weakness planes, respectively, and select the minimum value regarded as the integrated "BtS". The main steps can be concluded as follows: (1) Calculate the $B t S_{1}\left(\beta_{\mathrm{w}}\right)$ and $B t S_{2}\left(\beta_{\mathrm{w}}\right)$ for arbitrary weakness plane Nos. $1-i$ to obtain the "BtS" under tensile failure modes; (2) Set the radial ratio from 0 to 1 to calculate the "BtS" under shear failure modes, and calculate the $B t S_{3}\left(\beta_{\mathrm{w}}\right)$ and $B t S_{4}\left(\beta_{\mathrm{w}}\right)$ for arbitrary weakness plane Nos. 1-i to obtain the "BtS" under shear failure modes; (3) Calculate the integrated $B t S\left(\beta_{\mathrm{w}}\right)$ by selecting the minimum value for the $B t S_{1}\left(\beta_{\mathrm{w}}\right), B t S_{2}\left(\beta_{\mathrm{w}}\right)$, $B t S_{3}\left(\beta_{\mathrm{w}}\right)$ and $B t S_{4}\left(\beta_{\mathrm{w}}\right)$ from arbitrary weakness plane Nos. 1-i.

\subsubsection{Model Validation for Jixi Coal}

In order to demonstrate the performance of the generalized "BtS" modeling, the BDT results of Jixi Coal that were published by Li et al. (2016) [51] and Ai et al. (2015) [49] are utilized. The coal rocks are usually featured by well-developed both face and butt cleats, so the "BtS" of coal rocks are usually controlled by both face and butt cleats. According to the experimental results, set $a=0, c_{\mathrm{w}}^{(1)}=0.63 \mathrm{MPa}$, $\varphi_{\mathrm{w}}^{(1)}=16^{\circ}, c_{\mathrm{w}}^{(2)}=0.89 \mathrm{MPa}, \varphi_{\mathrm{w}}^{(2)}=20^{\circ}$, and $T_{\mathrm{m}}=T_{\mathrm{w}}=0.61 \mathrm{MPa}$, and the calculated result is shown in Figure 17 and Table 5. 


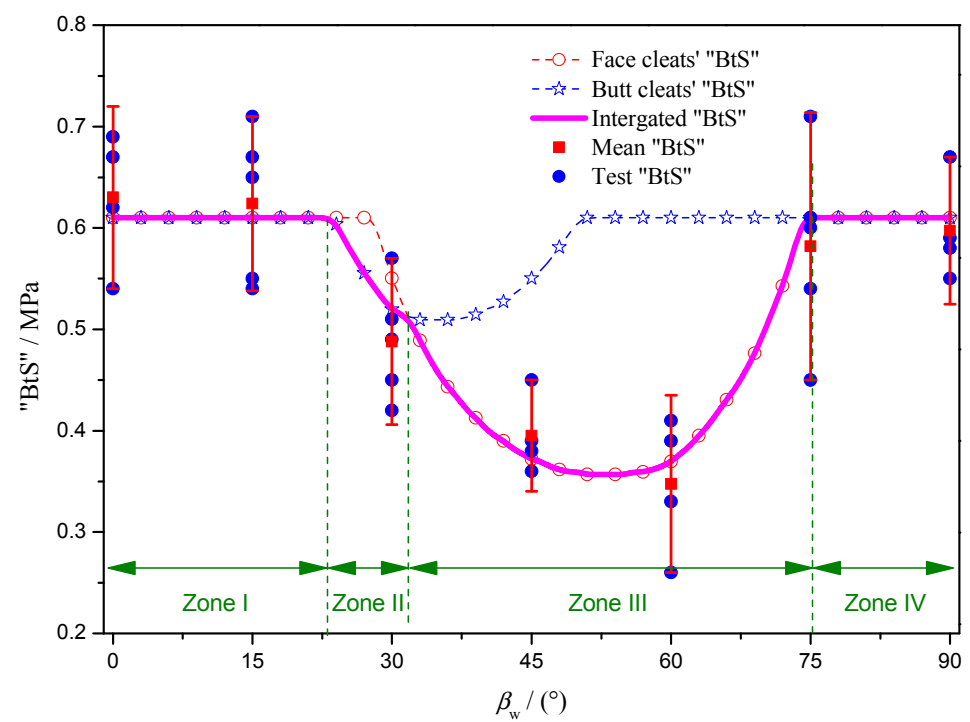

Figure 17. The contrast between the predicted and test "BtS" for Jixi Coal $(a=0)$.

Table 5. The BtS versus $\beta_{\mathrm{w}}$ of Jixi Coal (After Ai et al. 2015 [49]).

\begin{tabular}{cccccccc}
\hline \multirow{2}{*}{ No. } & \multicolumn{7}{c}{ BtS Versus $\beta_{\mathbf{w}} \mathbf{( M P a )}$} \\
\cline { 2 - 8 } & $\mathbf{0}^{\circ}$ & $\mathbf{1 5}^{\circ}$ & $\mathbf{3 0 ^ { \circ }}$ & $\mathbf{4 5 ^ { \circ }}$ & $\mathbf{6 0}^{\circ}$ & $\mathbf{7 5}^{\circ}$ & $\mathbf{9 0}^{\circ}$ \\
\hline 1 & 0.69 & 0.55 & 0.51 & 0.39 & 0.26 & 0.71 & 0.55 \\
2 & 0.54 & 0.65 & 0.45 & 0.45 & 0.41 & 0.45 & 0.59 \\
3 & 0.62 & 0.71 & 0.42 & 0.38 & 0.39 & 0.61 & 0.67 \\
4 & 0.67 & 0.67 & 0.49 & 0.36 & 0.33 & 0.6 & 0.58 \\
5 & - & 0.54 & 0.57 & - & - & 0.54 & - \\
Mean & 0.63 & 0.62 & 0.49 & 0.40 & 0.35 & 0.58 & 0.60 \\
Predicted BtS & 0.61 & 0.61 & 0.52 & 0.37 & 0.37 & 0.60 & 0.61 \\
Error & $3.17 \%$ & $1.61 \%$ & $6.12 \%$ & $7.50 \%$ & $5.71 \%$ & $3.45 \%$ & $1.67 \%$ \\
\hline
\end{tabular}

The failure modes of Jixi Coal can be concluded as follows: (1) When $0^{\circ} \leq \beta_{\mathrm{w}} \leq 23^{\circ}$, i.e., Zone I in Figure 17, the Brazilian disc experiences tensile failure; (2) When $23^{\circ} \leq \beta_{\mathrm{W}} \leq 32^{\circ}$, i.e., Zone II in Figure 17, the disc experiences shear failure along the butt cleats; (3) When $32^{\circ} \leq \beta_{\mathrm{W}} \leq 76^{\circ}$, i.e., Zone III in Figure 17, the disc experiences shear failure along the face cleats; (4) When $76^{\circ} \leq \beta_{\mathrm{w}} \leq 90^{\circ}$, i.e., Zone IV in Figure 17, the disc experiences tensile failure along. The predicted results are consistent with the test results, and the maximum deviation with the test results is $\sim 7.50 \%$. Therefore, the present method was successfully generalized for fractured rocks that contain multi-groups of weakness planes, and the current method (Li et al. [51]) is only a particular case.

\subsection{Discussion}

The BDT theory assumes that the tensile failure mode starts from the disc's center, but it is inconsistent with the typical failure patterns of anisotropic rocks, as shown in Figure 3. The typical failure patterns were classified into five categories: tensile failure across or along the weakness planes, shear failure across or along the weakness planes, and mixed failure. In case of shear failure across or along the weakness planes and mixed failure, the outcome of the BDT is definitely not the real tensile strength of the Brazilian disc. Therefore, an appropriate loading angle should be selected to test the real tensile strength in the Brazilian disc test of anisotropic rocks. Due to the impact of the loading angle, the failure mode no longer meets the connotative assumption that the tensile failure mode starts from the disc's center, the test result of BTD for anisotropic rock is also not the real Brazilian tensile strength, but an equivalent Brazilian Tensile Strength (BTS) or Brazilian test Strength ("BtS"). 
To explain the failure mechanisms and predict the "BtS", Liu et al. [39] and Li et al. [51] proposed two types of models to determine the strength of anisotropic rocks under BDT conditions. Liu et al. used the central stress state and the SPW theory to propose a "BtS" criterion for slate rocks [39]; Li et al. generalized the SPW theory into two groups of weakness planes to determine the "BtS" of jointed coal rocks [51]. However, some very important factors, such as the anisotropic tensile strength of anisotropic rocks, the initial fracture points of Brazilian disc, and the stress distribution on Brazilian disc, are ignored in current methods. Some of the results that were predicted by current methods are also inconsistent with the universal law. The transverse strength is usually higher than the longitudinal, but the transverse strength always equals to the longitudinal in their model. In the present model, the above-mentioned factors were involved to determine the strength of anisotropic rocks under BDT conditions. Therefore, the present method has a wider range of application, and the current methods that were published by Liu et al. [39] and Li et al. [51] are just some particular cases.

The connotative assumption in the present model is that the influence of the anisotropic modulus is ignored, and the anisotropic rock is simplified as a linear elastic, homogeneous and continuous media. In other words, only the anisotropic tensile and shear strengths were involved in the present model. Therefore, it can only be used to predict the "BtS" for anisotropic rocks with weak or medium anisotropy, but its influence should be considered for strong anisotropy because the anisotropic modulus has a notable effect on the stress distribution on the Brazilian disc.

The reason why we ignored the influence of the anisotropic modulus can be concluded as follows: (1) The anisotropy of the tensile strength usually outclasses the modulus for anisotropic rocks with weak or medium anisotropy [12], for instance, the anisotropic degree of modulus is 1.14-1.61 for Taiwan argillite, while its anisotropic degree of tensile strength is 11.17 [20]; the anisotropic degree of modulus is $~ 1.34$ for Mosel slate, while its anisotropic degree of tensile strength is 3.69 [45]; the anisotropic degree of modulus is $\sim 1.29$ for Longmaxi shale, while its anisotropic degree of tensile strength is $\sim 1.90$ [47]. (2) The closed-form elastic solution of stress distribution on the Brazilian disc for an anisotropic medium is difficult to obtain, and it is also very complex to apply in the determination of Brazilian disc failure. Since the BDT was developed in 1943 [22], the stress distribution on the Brazilian disc has received so much attention. Thereinto, the closed-form solution of stress distribution was proposed using the linear elastic theory, and the connotative assumption is that the influence of anisotropy on stress distribution is ignored. In 1957, Lekhnitskij proposed the elastic solution of stress distribution for an anisotropic medium [66,67], but only the stress distributions that were located on some key points/lines were obtained, due to their studies mainly focusing on the determination of anisotropic elastic constants and anisotropic indirect tensile strength [13,32,57,68-71]. In the present paper, the isotropic closed-form solution was used to simplify the complexity of the modeling. Of course, the influence of anisotropic modulus should be considered for strong anisotropy.

\section{Conclusions}

The present overview of 50+ years of development since the pioneering research of the 1960s is aimed to present the state of the art in the experimental studies on Brazilian tensile strength of anisotropic rocks. The statistical results of anisotropic degrees, variations of "BtS" with loading direction, and typical failure modes were reviewed for various anisotropic rocks. An integral understanding of the Brazilian tensile strength of anisotropic rocks appears. Based on the failure mechanisms, the typical failure modes were classified into five categories: tensile failure across and along the weakness planes, shear failure across and along the weakness planes, and mixed failure.

The anisotropic tensile and shear strength criteria were involved to propose a novel theoretical method to explain the failure mechanisms of anisotropic under BDT conditions. The present method has also been generalized for fractured rocks that contain multi-groups of weakness planes. The current method that was published by Li et al. [51] is just a particular case of the presented method. It can be utilized to calculate the anisotropic Brazilian test strength and simulate the failure patterns of the Brazilian disc. However, because the influence of the anisotropic modulus is ignored in the present 
model, it can be utilized only to predict the "BtS" of anisotropic rocks with weak or medium anisotropy, but its influence should be considered for strong anisotropy.

The BDT results of Longmaxi Shale-I and the Jixi Coal were used to demonstrate the performance of this anisotropic "BtS" modeling. The calculated "BtS" results are consistent with the test results. The maximum deviation with the test results is $\sim 6.55 \%$ for Longmaxi Shale-I and $\sim 7.50 \%$ for Jixi Coal. Thus, the present method is reasonable and accurate for the theoretical calculation of anisotropic "BtS" of anisotropic rocks. (1) For the Longmaxi Shale-I, when $0^{\circ} \leq \beta_{\mathrm{w}} \leq 24^{\circ}$, the Brazilian disc belongs tensile failure of intact rock; when $24^{\circ} \leq \beta_{\mathrm{w}} \leq 76^{\circ}$, the Brazilian disc belongs shear failure along the weakness planes; when $76^{\circ} \leq \beta_{\mathrm{w}} \leq 90^{\circ}$, the Brazilian disc belongs tensile failure along the weakness planes. The simulated failure patterns of the Longmaxi Shale-I are consistent with test results, it also demonstrated the performance of the present method. (2) For the Jixi Coal, when $0^{\circ} \leq \beta_{\mathrm{w}} \leq 23^{\circ}$ or $76^{\circ}$ $\leq \beta_{\mathrm{w}} \leq 90^{\circ}$, the Brazilian disc belongs tensile failure; when $23^{\circ} \leq \beta_{\mathrm{w}} \leq 32^{\circ}$, the Brazilian disc belongs shear failure along the butt cleats; when $32^{\circ} \leq \beta_{\mathrm{W}} \leq 76^{\circ}$, the Brazilian disc belongs shear failure along the face cleats.

Acknowledgments: This work was supported by the Fund of the State Key Laboratory of Oil and Gas Reservoir Geology and Exploitation of Southwest Petroleum University (Grant Nos. PLN201611 and G201604); the National Natural Science Foundation of China (Grant No. 51604230); the Young Elite Scientists Sponsorship Program by CAST (2017QNRC001); the Scientific Research Foundation of International Cooperation and Exchanges of Sichuan Province (Grant No. 2017HH0061).

Author Contributions: Tianshou Ma, Nian Peng and Qianbing Zhang designed the study. Tianshou Ma, Nian Peng, Zhu Zhu and Qianbing Zhang conducted the numerical simulation, analysed the data and wrote the paper. Chunhe Yang and Jian Zhao reviewed the manuscript. All the authors read and confirmed the final manuscript.

Conflicts of Interest: The authors declare no conflict of interest.

\section{List of Symbols}

\begin{tabular}{|c|c|}
\hline$A I$ & The anisotropic index \\
\hline$B t S_{\max }$ & The maximum "BtS", $\mathrm{MPa}$ \\
\hline$B t S_{\min }$ & The minimum "BtS", $\mathrm{MPa}$ \\
\hline$P$ & The line load, $\mathrm{N}$ \\
\hline$D$ & The diameter of the disc, $\mathrm{mm}$ \\
\hline$t$ & The thickness of the disc, $\mathrm{mm}$ \\
\hline$r_{1}, r_{2}$ & The distances from arbitrary point to the upper and lower loading points respectively, $\mathrm{mm}$ \\
\hline$\theta_{1}, \theta_{2}$ & $\begin{array}{l}\text { The intersection angle between loading position and the ligature form arbitrary point to the } \\
\text { upper and lower loading points respectively, }\left(^{\circ}\right)\end{array}$ \\
\hline$x, y$ & The rectangular coordinates of the arbitrary point, $\mathrm{mm}$ \\
\hline$\sigma_{X X}, \sigma_{Y Y}$ & The stress along $X$ and $Y$ axis respectively, $\mathrm{MPa}$ \\
\hline$\tau_{X Y}$ & The shear stress, $\mathrm{MPa}$ \\
\hline$\sigma_{x x}, \sigma_{y y}$ & The stress along $x$ and $y$ axis respectively, $\mathrm{MPa}$ \\
\hline$\tau_{x y}$ & The shear stress, $\mathrm{MPa}$ \\
\hline$\beta_{\mathrm{w}}$ & The complementary angles of foliation-loading angle, $\left({ }^{\circ}\right)$ \\
\hline$\sigma_{1}$ & The maximum principal stress, $\mathrm{MPa}$ \\
\hline$\sigma_{3}$ & The minimum principal stress, $\mathrm{MPa}$ \\
\hline$\beta_{\mathrm{f}}$ & The potential failure direction of rock, $\left({ }^{\circ}\right)$ \\
\hline$\sigma_{\mathrm{nw}}$ & The normal tensile stress load on the surface of weakness planes, $\mathrm{MPa}$ \\
\hline$T_{\mathrm{w}}$ & The tensile strength of weakness planes, $\mathrm{MPa}$ \\
\hline$\beta_{\mathrm{w}}^{*}$ & The critical angle, $\left({ }^{\circ}\right)$ \\
\hline$B t S_{1}\left(\beta_{\mathrm{W}}\right)$ & The calculated "BtS" for tensile failure across the weakness planes, MPa. \\
\hline$B t S_{2}\left(\beta_{\mathrm{w}}\right)$ & The calculated "BtS" for tensile failure along the weakness planes, $\mathrm{MPa}$. \\
\hline$\tau_{0}$ & The resultant shear stress load on the shear plane, $\mathrm{MPa}$ \\
\hline$\tau_{\mathrm{w}}$ & The resultant shear stress load on the surface of the WPs, MPa \\
\hline$\sigma_{\mathrm{n} 0}$ & The resultant effective normal stress load on the shear plane, $\mathrm{MPa}$ \\
\hline
\end{tabular}




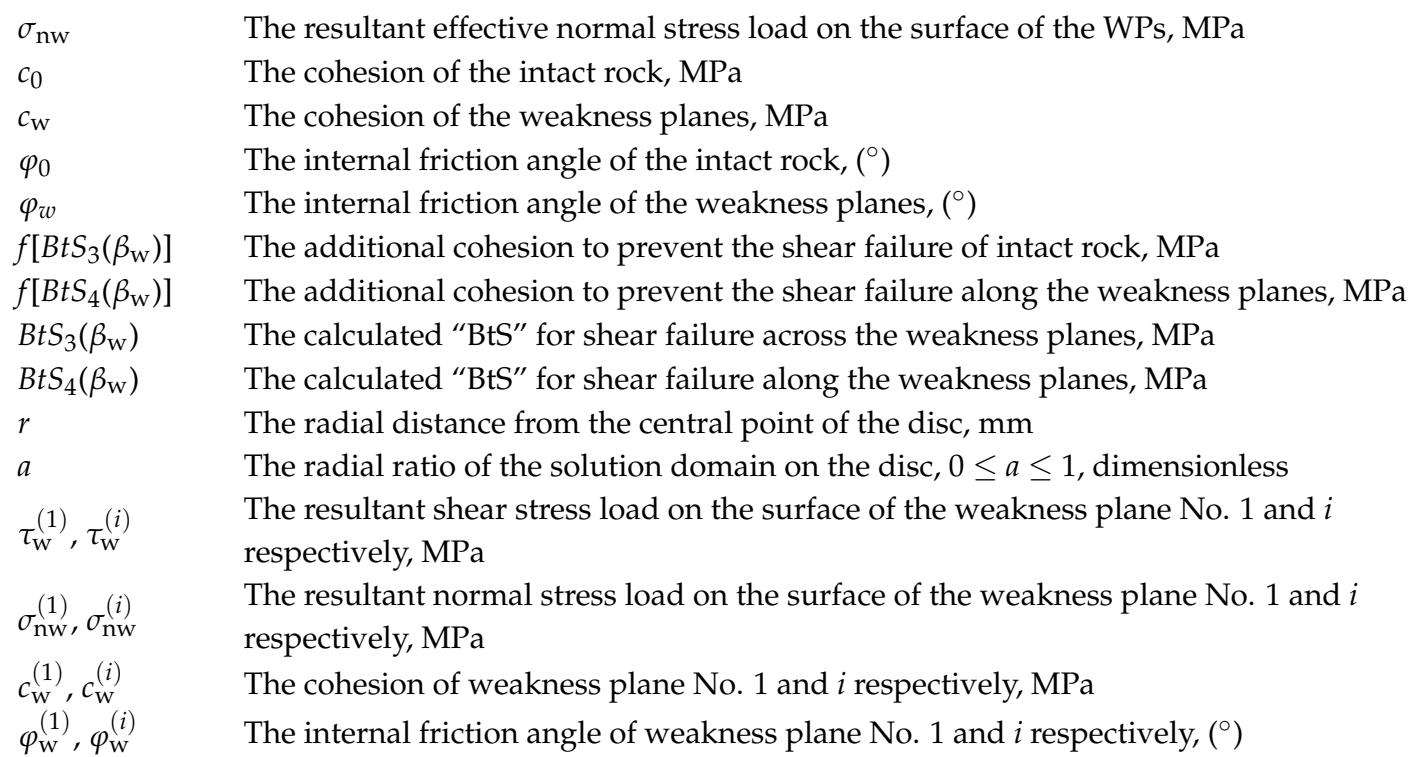

\section{Abbreviations}

$\begin{array}{ll}\text { DTT } & \text { Direct Tensile Test } \\ \text { ITT } & \text { Indirect Tensile Test } \\ \text { BDT } & \text { Brazilian Disc Test } \\ \text { ITS } & \text { Indirect Tensile Strength } \\ \text { BTS } & \text { Brazilian Tensile Strength } \\ \text { "BtS" } & \text { Brazilian test Strength } \\ \text { SPW } & \text { Single Plane of Weakness }\end{array}$

\section{Appendix A. Classical Theories of BDT}

As shown in Figure 7, the isotropic closed-form solution of stress distribution on the Brazilian disc can be written as $[22,70]$ :

$$
\left\{\begin{array}{l}
\sigma_{X X}=\frac{2 P}{\pi t}\left(\frac{\cos \theta_{1} \sin ^{2} \theta_{1}}{r_{1}}+\frac{\cos \theta_{2} \sin ^{2} \theta_{2}}{r_{2}}\right)-\frac{2 P}{\pi D t} \\
\sigma_{Y Y}=\frac{2 P}{\pi t}\left(\frac{\cos ^{3} \theta_{1}}{r_{1}}+\frac{\cos ^{3} \theta_{2}}{r_{2}}\right)-\frac{2 P}{\pi D t} \\
\tau_{X Y}=\frac{2 P}{\pi t}\left(\frac{\cos ^{2} \theta_{1} \sin \theta_{1}}{r_{1}}+\frac{\cos ^{2} \theta_{2} \sin \theta_{2}}{r_{2}}\right)
\end{array}\right.
$$

The failure of Brazilian disc is determined using the Griffith criterion in the classical BDT theory. According to the stress state of the central point and the Griffith criterion, the tensile strength of Brazilian disc can be expressed as $[22,70]$ :

$$
B T S=-\frac{2 P}{\pi D t}
$$

\section{References}

1. Jaeger, J.C.; Cook, N.G.W.; Zimmerman, R.W. Fundamentals of Rock Mechanics, 4th ed.; Blackwell Publishing: Hoboken, NJ, USA, 2007.

2. Cho, J.W.; Kim, H.; Jeon, S.; Min, K.B. Deformation and strength anisotropy of Asan gneiss, Boryeong shale, and Yeoncheon schist. Int. J. Rock Mech. Min. Sci. 2012, 50, 158-169. [CrossRef]

3. Wittke, W. Rock Mechanics Based on an Anisotropic Jointed Rock Model (AJRM); Wilhelm Ernst \& Sohn: Weinheim, Germany, 2014.

4. Fereidooni, D.; Khanlari, G.R.; Heidari, M.; Sepahi-Gero, A.A.; Kolahi-Azar, A.P. Assessment of inherent anisotropy and confining pressure influences on mechanical behavior of anisotropic foliated rocks under triaxial compression. Rock Mech. Rock Eng. 2016, 49, 2155-2163. [CrossRef]

5. Aadnoy, B.; Looyeh, R. Petroleum Rock Mechanics: Drilling Operations and Well Design; Gulf Professional Publishing: Houston, TX, USA, 2011. 
6. Ma, T.; Chen, P. Study of meso-damage characteristics of shale hydration based on CT scanning technology. Pet. Explor. Dev. 2014, 41, 249-256. [CrossRef]

7. Ma, T.; Chen, P. A wellbore stability analysis model with chemical-mechanical coupling for shale gas reservoirs. J. Nat. Gas Sci. Eng. 2015, 26, 72-98. [CrossRef]

8. Chen, P.; Han, Q.; Ma, T.S.; Lin, D. The mechanical properties of shale based on micro-indentation test. Pet. Explor. Dev. 2015, 42, 723-732. [CrossRef]

9. Heng, S.; Guo, Y.; Yang, C.; Daemen, J.J.K.; Li, Z. Experimental and theoretical study of the anisotropic properties of shale. Int. J. Rock Mech. Min. Sci. 2015, 74, 58-68. [CrossRef]

10. Ma, T.; Chen, P.; Yang, C.; Zhao, J. Wellbore stability analysis and well path optimization based on the breakout width model and Mogi-Coulomb criterion. J. Pet. Sci. Eng. 2015, 135, 678-701. [CrossRef]

11. Ma, T.; Zhang, Q.B.; Chen, P.; Yang, C.; Zhao, J. Fracture pressure model for inclined wells in layered formations with anisotropic rock strengths. J. Pet. Sci. Eng. 2017, 149, 393-408. [CrossRef]

12. Ma, T.; Wu, B.; Fu, J.; Zhang, Q.; Chen, P. Fracture pressure prediction for layered formations with anisotropic rock strengths. J. Nat. Gas Sci. Eng. 2017, 38, 485-503. [CrossRef]

13. Amadei, B.; Orszag, S.A. Rock Anisotropy and the Theory of Stress Measurements; Springer: Berlin/Heidelberg, Germany, 1983.

14. Jaeger, J.C. Shear failure of anisotropic rocks. Geol. Mag. 1960, 97, 65-72. [CrossRef]

15. Jaeger, J.C. Friction of rocks and stability of rock slopes. Geotechnique 1971, 21, 97-134. [CrossRef]

16. Lisjak, A.; Tatone, B.S.A.; Grasselli, G.; Vietor, T. Numerical modelling of the anisotropic mechanical behaviour of Opalinus Clay at the laboratory-scale using FEM/DEM. Rock Mech. Rock Eng. 2014, 47, 187-206. [CrossRef]

17. Khanlari, G.; Rafiei, B.; Abdilor, Y. An experimental investigation of the Brazilian tensile strength and failure patterns of laminated sandstones. Rock Mech. Rock Eng. 2015, 48, 843-852. [CrossRef]

18. Khanlari, G.R.; Heidari, M.; Sepahigero, A.A.; Fereidooni, D. Quantification of strength anisotropy of metamorphic rocks of the Hamedan province, Iran, as determined from cylindrical punch, point load and Brazilian tests. Eng. Geol. 2014, 169, 80-90. [CrossRef]

19. Khanlari, G.R.; Heidari, M.; Sepahi-Gero, A.A.; Fereidooni, D. Determination of geotechnical properties of anisotropic rocks using some index tests. Geotech. Test. J. 2014, 37, 1-13. [CrossRef]

20. Liao, J.J.; Yang, M.T.; Hsieh, H.Y. Direct tensile behavior of a transversely isotropic rock. Int. J. Rock Mech. Min. Sci. 1997, 34, 837-849. [CrossRef]

21. Lee, Y.K.; Pietruszczak, S. Tensile failure criterion for transversely isotropic rocks. Int. J. Rock Mech. Min. Sci. 2015, 79, 205-215. [CrossRef]

22. Akazawa, T. New test method for evaluating internal stress due to compression of concrete: The splitting tension test. J. Jpn. Soc. Civ. Eng. 1943, 29, 777-787.

23. Carneiro, F.L.L.B. A new method to determine the tensile strength of concrete. In Proceedings of the 5th Meeting of the Brazilian Association for Technical Rules, 3rd Section, Lisbon, Portugal, 16 September 1943; pp. 126-129.

24. Jianhong, Y.; Wu, F.Q.; Sun, J.Z. Estimation of the tensile elastic modulus using Brazilian disc by applying diametrically opposed concentrated loads. Int. J. Rock Mech. Min. Sci. 2009, 46, 568-576. [CrossRef]

25. Dan, D.Q.; Konietzky, H.; Herbst, M. Brazilian tensile strength tests on some anisotropic rocks. Int. J. Rock Mech. Min. Sci. 2013, 58, 1-7. [CrossRef]

26. Dan, D.Q.; Konietzky, H. Numerical simulations and interpretations of Brazilian tensile tests on transversely isotropic rocks. Int. J. Rock Mech. Min. Sci. 2014, 71, 53-63. [CrossRef]

27. Li, D.; Wong, L.N.Y. The Brazilian disc test for rock mechanics applications: Review and new insights. Rock Mech. Rock Eng. 2013, 46, 269-287. [CrossRef]

28. Duan, K.; Kwok, C.Y. Discrete element modeling of anisotropic rock under Brazilian test conditions. Int. J. Rock Mech. Min. Sci. 2015, 78, 46-56. [CrossRef]

29. Kwok, C.Y.; Duan, K. DEM simulation of fracture process of inherently anisotropic rock under Brazilian test condition. In Proceedings of the 49th US Rock Mechanics/Geomechanics Symposium, San Francisco, CA, USA, 28 June-1 July 2015; ARMA 15-535.

30. Hobbs, D.W. The tensile strength of rocks. Int. J. Rock Mech. Min. Sci. Geomech. Abstr. 1964, 1, $385-396$. [CrossRef]

31. Barla, G.; Innaurato, N. Indirect tensile testing of anisotropic rocks. Rock Mech. 1973, 5, 215-230. [CrossRef] 
32. Chou, Y.C.; Chen, C.S. Determining elastic constants of transversely isotropic rocks using Brazilian test and iterative procedure. Int. J. Numer. Anal. Methods Geomech. 2008, 32, 219-234. [CrossRef]

33. Debecker, B.; Vervoort, A. Experimental observation of fracture patterns in layered slate. Int. J. Fract. 2009, 159, 51-62. [CrossRef]

34. Tavallali, A.; Vervoort, A. Effect of layer orientation on the failure of layered sandstone under Brazilian test conditions. Int. J. Rock Mech. Min. Sci. 2010, 47, 313-322. [CrossRef]

35. Tavallali, A.; Vervoort, A. Failure of layered sandstone under Brazilian test conditions: Effect of micro-scale parameters on macro-scale behaviour. Rock Mech. Rock Eng. 2010, 43, 641-653. [CrossRef]

36. Tavallali, A.; Vervoort, A. Behaviour of layered sandstone under Brazilian test conditions: Layer orientation and shape effects. J. Rock Mech. Geotech. Eng. 2013, 5, 366-377. [CrossRef]

37. Liu, Y.S.; Fu, H.L.; Rao, J.Y.; Dong, H.; Cao, Q. Research on Brazilian disc splitting tests for anisotropy of slate under influence of different bedding orientations. Chin. J. Rock Mech. Eng. 2012, 31, 785-791.

38. Liu, S.L.; Chen, S.X.; Yu, F.; Zhao, W.G. Anisotropic properties study of chlorite schist. Rock Soil Mech. 2012, 33, 3616-3623.

39. Liu, Y.S.; Fu, H.L.; Wu, Y.M.; He, Y.W.; Dong, H. Study on Brazilian splitting test for slate based on single weak plane theory. J. China Coal Soc. 2013, 38, 1775-1780.

40. Simpson, N.D.J. An analysis of Tensile Strength, Fracture Initiation and Propagation in Anisotropic Rock (Gas Shale) Using Brazilian Tests Equipped with High Speed Video and Acoustic Emission. Master's Thesis, Norwegian University of Science and Technology, Trondheim, Norway, 2013.

41. Tan, X.; Heinz, K. Brazilian split tests and numerical simulation by discrete element method for heterogeneous gneiss with bedding structure. Chin. J. Rock Mech. Eng. 2014, 33, 938-946.

42. Mighani, S.; Sondergeld, C.; Rai, C. Efficient completions in anisotropic shale gas formations. In Proceedings of the Unconventional Resources Technology Conference (URTEC), Denver, CO, USA, 25-27 August 2014; URTeC 1934272.

43. Mighani, S.; Sondergeld, C.H.; Rai, C.S. Observations of tensile fracturing of anisotropic rocks. SPE J. 2016, 21, 1-13. [CrossRef]

44. Beyhan, S.; Özgür, A. Investigating the anisotropy of rocks depending on the indirect tensile strength. In Proceedings of the ISRM Regional Symposium-EUROCK, Salzburg, Austria, 7-10 October 2015; ISRM-EUROCK-2015-088.

45. Tan, X.; Konietzky, H.; Frühwirt, T.; Dan, D.Q. Brazilian tests on transversely isotropic rocks: Laboratory testing and numerical simulations. Rock Mech. Rock Eng. 2015, 48, 1341-1351. [CrossRef]

46. Wang, X. Experimental study on the effect of micro-cracks on Brazilian tensile strength. Arch. Min. Sci. 2015, 60, 985-996. [CrossRef]

47. Yang, Z.P.; He, B.; Xie, L.Z.; Li, C.; Wang, J. Strength and failure modes of shale based on Brazilian test. Rock Soil Mech. 2015, 36, 3447-3455.

48. Yao, G.H.; Chen, Q.; Liu, H.; Tan, Y.H.; Wang, L.S.; Du, H.Y.; Zhu, H.L. Experiment study on mechanical properties of bedding shale in lower Silurian Longmaxi shale southeast Chongqing. Chin. J. Rock Mech. Eng. 2015, 34 (Suppl. S1), 3313-3319.

49. Ai, C.; Zhang, J.; Li, Y.; Zeng, J.; Gao, C. Theoretical calculation and experimental research on tensile strength of coal rock under different splitting angles. Saf. Coal Mines 2015, 46, 20-23.

50. Li, Y.D.; Qiu, J.D.; Li, X.B. Experimental study on dynamic tensile and compressive properties of bedding sandstone under impact loading. Chin. J. Rock Mech. Eng. 2015, 34, 2091-2097.

51. Li, Y.W.; Zhang, J.; Liu, Y. Effects of loading direction on failure load test results for Brazilian tests on coal rock. Rock Mech. Rock Eng. 2016, 49, 2173-2180. [CrossRef]

52. Roy, D.G.; Singh, T.N. Effect of Heat Treatment and layer orientation on the tensile strength of a crystalline rock under Brazilian test condition. Rock Mech. Rock Eng. 2016, 49, 1663-1677.

53. Hou, P.; Gao, F.; Yang, Y.G.; Zhang, Z.Z.; Zhang, X.X. Effect of layer orientation on the failure of block shale under Brazilian splitting test and energy analysis. Chin. J. Geotech. Eng. 2016, 38, 930-937.

54. Hou, P.; Gao, F.; Zhang, Z.Z.; Lin, B.; Yang, Y.G.; Gao, Y.N. Mechanical property and bedding inclination effect on gas fracturing of black shale. Chin. J. Rock Mech. Eng. 2016, 35, 670-681.

55. Wang, J.; Xie, L.; Xie, H.; Ren, L.; He, B.; Li, C.; Yang, Z.; Gao, C. Effect of layer orientation on acoustic emission characteristics of anisotropic shale in Brazilian tests. J. Nat. Gas Sci. Eng. 2016, 36, 1120-1129. [CrossRef] 
56. Singh, J.; Ramamurthy, T.; Rao, G.V. Strength anisotropies in rocks. Indian Geotech. J. 1989, 19, 147-166.

57. Chen, C.S.; Pan, E.; Amadei, B. Determination of deformability and tensile strength of anisotropic rock using Brazilian tests. Int. J. Rock Mech. Min. Sci. 1998, 35, 43-61. [CrossRef]

58. Zhao, Y.; Zhao, G.F.; Jiang, Y.; Elsworth, D.; Huang, Y.Q. Effects of bedding on the dynamic indirect tensile strength of coal: Laboratory experiments and numerical simulation. Int. J. Coal Geol. 2014, 132, 81-93. [CrossRef]

59. Zhao, Y.; Liu, S.; Jiang, Y.; Wang, K.; Huang, Y. Dynamic tensile strength of coal under dry and saturated conditions. Rock Mech. Rock Eng. 2016, 49, 1709-1720. [CrossRef]

60. Mokhtari, M.; Bui, B.T.; Tutuncu, A.N. Tensile failure of shales: Impacts of layering and natural fractures. In Proceedings of the SPE Western North American and Rocky Mountain Joint Meeting, Denver, CO, USA, 17-18 April 2014; SPE 169520.

61. Park, B.; Min, K.B. Bonded-particle discrete element modeling of mechanical behavior of transversely isotropic rock. Int. J. Rock Mech. Min. Sci. 2015, 76, 243-255. [CrossRef]

62. Hobbs, D.W. Rock tensile strength and its relationship to a number of alternative measures of rock strength. Int. J. Rock Mech. Min. Sci. Geomech. Abstr. 1967, 4, 115-127. [CrossRef]

63. Nova, R.; Zaninetti, A. An investigation into the tensile behaviour of a schistose rock. Int. J. Rock Mech. Min. Sci. Geomech. Abstr. 1990, 27, 231-242. [CrossRef]

64. Duveau, G.; Shao, J.F.; Henry, J.P. Assessment of some failure criteria for strongly anisotropic geomaterials. Mech. Cohesive Frict. Mater. 1998, 3, 1-26. [CrossRef]

65. Ma, T.; Chen, P.; Zhang, Q.; Zhao, J. A novel collapse pressure model with chemical-mechanical coupling in shale gas formations with multi-weakness planes. J. Nat. Gas Sci. Eng. 2016, 36, 1151-1177. [CrossRef]

66. Lekhnitskii, S.G. Anisotropic Plates; Gorden and Breach: New York, NY, USA, 1957.

67. Lekhnitskij, S.G. Theory of the Elasticity of Anisotropic Bodies; Mir Publishers: Moscow, Russia, 1981.

68. Loureiro-Pinto, J. Determination of the elastic constants of anisotropic bodies by diametral compression tests. In Proceedings of the 4th ISRM Congress, Montreux, Switzerland, 2-8 September 1979; ISRM-4CONGRESS-1979-160.

69. Chen, C.S.; Pan, E.; Amadei, B. Evaluation of properties of anisotropic rocks using Brazilian tests. In Proceedings of the 2nd North American Rock Mechanics Symposium, Montreal, QC, Canada, 19-21 June 1996; ARMA 96-1651.

70. Claesson, J.; Bohloli, B. Brazilian test: Stress field and tensile strength of anisotropic rocks using an analytical solution. Int. J. Rock Mech. Min. Sci. 2002, 39, 991-1004. [CrossRef]

71. Cai, M. Practical estimates of tensile strength and Hoek-Brown strength parameter $m_{i}$ of brittle rocks. Rock Mech. Rock Eng. 2010, 43, 167-184. [CrossRef] 